\title{
Dorsal Horn Neurons Firing at High Frequency, But Not Primary Afferents, Release Opioid Peptides that Produce $\mu$-Opioid Receptor Internalization in the Rat Spinal Cord
}

\author{
Bingbing Song and Juan Carlos G. Marvizón \\ Center for Neurovisceral Sciences and Women's Health, Division of Digestive Diseases, Department of Medicine, David Geffen School of Medicine at \\ University of California Los Angeles, Los Angeles, California 90073
}

To determine what neural pathways trigger opioid release in the dorsal horn, we stimulated the dorsal root, the dorsal horn, or the dorsolateral funiculus (DLF) in spinal cord slices while superfusing them with peptidase inhibitors to prevent opioid degradation. Internalization of $\mu$-opioid receptors (MOR) and neurokinin 1 receptors (NK1R) was measured to assess opioid and neurokinin release, respectively. Dorsal root stimulation at low, high, or mixed frequencies produced abundant NK1R internalization but no MOR internalization, indicating that primary afferents do not release opioids. Moreover, capsaicin and NMDA also failed to produce MOR internalization. In contrast, dorsal horn stimulation elicited MOR internalization that increased with the frequency, being negligible at $<10 \mathrm{~Hz}$ and maximal at $500 \mathrm{~Hz}$. The internalization was abolished by the MOR antagonist D-Phe-Cys-Tyr-D-Trp-Arg-Thr-Pen-Thr-NH ${ }_{2}(\mathrm{CTAP})$, in the presence of low $\mathrm{Ca}^{2+}$ and by the $\mathrm{Na}^{+}$channel blocker lidocaine, confirming that it was caused by opioid release and neuronal firing. DLF stimulation in "oblique" slices (encompassing the DLF and the dorsal horn of T11-L4) produced MOR internalization, but only in areas near the stimulation site. Moreover, cutting oblique slices across the dorsal horn (but not across the DLF) eliminated MOR internalization in areas distal to the cut, indicating that it was produced by signals traveling in the dorsal horn and not via the DLF. These findings demonstrate that some dorsal horn neurons release opioids when they fire at high frequencies, perhaps by integrating signals from the rostral ventromedial medulla, primary afferents, and other areas of the spinal cord.

Key words: C-fiber; dynorphin; endocytosis; endomorphin; enkephalin; dorsal horn; dorsolateral funiculus; internalization; neurokinin; neurokinin 1 receptor; $\mu$-opioid receptor; opioid; primary afferent; rat; release; spinal cord; substance P; tachykinin

\section{Introduction}

The spinal dorsal horn contributes to the powerful analgesic actions of the opioid system (Yaksh, 1987; Kanjhan, 1995; Przewlocki and Przewlocka, 2001). It contains abundant opioid peptides and $\delta$-, $\kappa$ - and $\mu$-opioid receptors (MOR) (Quirion, 1984; Todd and Spike, 1993; Mansour et al., 1995). In particular, MORs are present in primary afferents (Yaksh et al., 1980; Abbadie et al., 2001) and in lamina II excitatory interneurons (Kemp et al., 1996).

Little is known about the neural pathways that trigger opioid release in the dorsal horn. One of them may be the periaqueductal gray (PAG)-rostral ventromedial medulla (RVM)-dorsal horn pathway, because of its analgesic actions (Basbaum et al., 1976; Basbaum and Fields, 1984; Fields et al., 1991; Mason, 1999). Indeed, analgesia induced by PAG stimulation was reversed by spinal application of MOR antagonists (Budai and Fields, 1998).

Received July 17, 2003; revised Aug. 21, 2003; accepted Aug. 26, 2003.

This work was supported by National Institute on Drug Abuse Grant R01-DA12609 to J.C.M. We thank Drs. Chris Evans, Marzia Malcangio, Emeran Mayer, Enrico Stefani, and Ligia Toro for their support, and Dr. Lijun Lao and Narek Garukyan for their help. We are also grateful for the assistance of Dr. Matthew J. Schibler at the Carol Moss Spivak Cell Imaging Facility of the University of California Los Angeles.

Correspondence should be addressed to Juan Carlos G. Marvizón, West Los Angeles Veterans Affairs Medical Center, Building 115, Room 119, 11301 Wilshire Boulevard, Los Angeles, CA 90073. E-mail: marvizon@ucla.edu. Copyright $\odot 2003$ Society for Neuroscience $\quad 0270-6474 / 03 / 239171-14 \$ 15.00 / 0$
Nociceptive modality, i.e., chemical (Bourgoin et al., 1990) and thermal (Cesselin et al., 1989) versus mechanical (Le Bars et al., $1987 \mathrm{a}, \mathrm{b})$, seems to determine whether Met-enkephalin is released from the spinal segment receiving the stimulus or from unrelated ones. It is not clear, however, whether spinal opioid release evoked by peripheral nerve stimulation is mediated supraspinally (Hutchison et al., 1990) or not (Yaksh and Elde, 1981). Primary afferents may release endomorphins (Martin-Schild et al., 1998; Pierce et al., 1998; Spike et al., 2002; but see Schreff et al., 1998; Marvizón and Song, 2002) or dynorphins, either directly (Basbaum et al., 1986; Sweetnam et al., 1986; Ribeiro-da-Silva and Claudio Cuello, 1995) or indirectly (Cho and Basbaum, 1989).

Traditional approaches to study opioid release present several problems. First, because there are many opioid peptides, measuring just one may miss the physiological actions of others (Yaksh et al., 1983). Second, it is difficult to relate opioid release with receptor activation. Third, noxious stimulation may not be an effective way to evoke opioid release (Trafton et al., 2000). Fourth, the whole animal may be too complex to pinpoint the neural pathways involved. One way to deal with the first two problems is to measure receptor internalization (Eckersell et al., 1998; Marvizón et al., 1999a), as has been done to measure neurokinin release (Mantyh et al., 1995; Abbadie et al., 1997; Allen et al., 1997, 1999; Liu et al., 1997; Marvizón et al., 1997, 1999b, 2003; 
Honore et al., 1999; Trafton et al., 1999, 2001). Admittedly, the relationship between MOR activation and its internalization is complex (Keith et al., 1996, 1998; Alvarez et al., 2002); however, all endogenous opioids tested produced MOR internalization (Song and Marvizón, 2003). Dealing with the second and third problems requires approaches allowing the stimulation of specific pathways in the absence of others.

We investigated the contribution of different neural pathways to opioid release in the dorsal horn by measuring MOR internalization. Spinal cord slices were used to electrically stimulate primary afferents, dorsal horn neurons, or the dorsolateral funiculus (DLF).

\section{Materials and Methods}

Chemicals. Isoflurane was from Halocarbon Laboratories (River Edge, NJ). Normal goat serum was from Jackson ImmunoResearch Laboratories (West Grove, PA). Prolong was from Molecular Probes (Eugene, OR). Other chemicals used were purchased from Sigma/RBI (St. Louis, $\mathrm{MO})$. Capsaicin was dissolved in ethanol, and NMDA was dissolved in $0.1 \mathrm{M} \mathrm{KOH}$ to get stock solutions of 100 and $10 \mathrm{~mm}$, respectively.

Media for slices. Artificial CSF (aCSF) contained (in mM): $124 \mathrm{NaCl}, 1.9$ $\mathrm{KCl}, 26 \mathrm{NaHCO}_{3}, 1.2 \mathrm{KH}_{2} \mathrm{PO}_{4}, 1.3 \mathrm{MgSO}_{4}, 2.4 \mathrm{CaCl}_{2}$, and 10 glucose. $\mathrm{K}^{+}$-aCSF contained a higher concentration $(5 \mathrm{~mm})$ of $\mathrm{KCl}$. SucroseaCSF was identical to aCSF, except that $\mathrm{NaCl}$ was iso-osmotically replaced by sucrose $(215 \mathrm{~mm}$ ) and the concentration of $\mathrm{KCl}$ was $5 \mathrm{~mm}$. In one experiment the concentration of $\mathrm{CaCl}_{2}$ in aCSF was decreased to 0.2 $\mathrm{mm}$. All of these media were bubbled constantly with $95 \% \mathrm{O}_{2} / 5 \% \mathrm{CO}_{2}$ for oxygenation and a $\mathrm{pH}$ of 7.4 .

Coronal spinal cord slice preparation. All animal procedures were approved by the Chancellor's Animal Research Committee at University of California Los Angeles and conform to National Institutes of Health guidelines. Efforts were made to minimize the number of animals used and their suffering. Coronal slices were prepared as described previously (Randic et al., 1993; Marvizón et al., 1997, 1999a,b; Sandkuhler et al., 1997). Briefly, Sprague Dawley rats 3-4 weeks old (Harlan, Indianapolis, IND) were anesthetized with isoflurane. A lumbar segment of the spinal cord was rapidly extracted, placed in ice-cold sucrose-aCSF, and cleaned of dura mater and ventral roots. The spinal cord segment was glued vertically to a block of agar on the stage of a Vibratome (Technical Products International, St. Louis, MO) with a stereo microscope (PZM, World Precision Instruments, Sarasota, FL) mounted over it. Coronal spinal cord slices $(400 \mu \mathrm{m})$ were cut in ice-cold sucrose-aCSF, using minimum forward speed and maximum vibration amplitude. Up to six slices were obtained from each animal in the L1-L4 region. To prepare slices without roots, all dorsal roots were cut away and the slices were cut sequentially. To prepare slices with dorsal roots, selected roots were lightly pulled to separate them from the spinal cord. The blade of the Vibratome was carefully aimed just caudal to the entrance of the root, and a first cut was made; then the root was moved over the blade, and a second cut was made $400 \mu \mathrm{m}$ rostral of the first cut. Fiber continuity between the root and the dorsal funiculus was assessed by examining the dorsal surface of the slice with the stereo microscope; only slices with $>80 \%$ of the dorsal funiculus continuous with the root were used. After cutting, slices were kept for $1 \mathrm{hr}$ in $\mathrm{K}^{+}-\mathrm{aCSF}$ at $35^{\circ} \mathrm{C}$ and then transferred to aCSF at $35^{\circ} \mathrm{C}$.

Oblique spinal cord slice preparation. Oblique spinal cord slices are a new preparation encompassing the DLF and the dorsal horn of one side of the spinal cord for six to seven spinal segments (typically, T11-L4). They were cut in a plane $45^{\circ}$ between the horizontal and the sagittal planes. Their preparation was similar to that of coronal slices, except as follows. A prism of agar $(15 \times 15 \times 20 \mathrm{~mm})$ was cut along the diagonal of its square base to make an agar wedge with a plane at a $45^{\circ}$ angle. One of the sharp corners of the agar wedge was cut $8 \mathrm{~mm}$ from the edge to make a flat surface. The agar wedge was glued to the stage of the Vibratome with its sloping side facing the blade and precisely aligned with it. A spinal cord segment, approximately T10-L6, was extracted from an anesthetized rat and cleaned. To help locate spinal cord segments, the T11 and L3 dorsal roots were left intact and the others were cut. The spinal cord was placed on the flat surface on top of the agar wedge with its ventral side facing toward the blade, carefully aligning it with the edge of the wedge. Loctite glue (Ted Pella Inc., Redding, CA) was applied to the slopping face of the agar, and the spinal cord was carefully rolled onto it to glue its ventral side to the wedge, paying attention to keep the spinal cord aligned to the edge of the wedge. The blade of the Vibratome was positioned so that it just touched the top of the spinal cord, retracted, and brought down $700 \mu \mathrm{m}$ (approximately to the center of the dorsal funiculus), and the slice was cut. The correct geometry of the slice was confirmed by inspecting transversal sections of the remaining spinal cord.

Electrical stimulation of the dorsal root. Coronal slices with attached roots were placed in a custom-made slice chamber (a gift from Dr. Marzia Malcangio, King's College of London, London, UK) and superfused at a rate of $3-6 \mathrm{ml} / \mathrm{min}$ with aCSF at $35^{\circ} \mathrm{C}$ saturated with $95 \% \mathrm{O}_{2} / 5 \%$ $\mathrm{CO}_{2}$ and containing phosphoramidon, captopril, and actinonin (all 10 $\mu \mathrm{M}$ ). The bipolar electrode consisted of two platinum wires (diameter 0.5 $\mathrm{mm}$ ) separated $1 \mathrm{~mm}$ that were located in a compartment separated from the superfusion chamber by a partition with two small holes sealed with vacuum grease. The dorsal root was drawn into the electrode compartment through one of the holes and placed on top of the platinum wires. The electrode compartment was then emptied of aCSF and filled with mineral oil. Contact between the root and the electrode wires and the thickness of the sheet of aCSF surrounding the root was checked with a stereo microscope, and any excess aCSF short-circuiting the electrode was eliminated. Electrical stimulation was generated by a Grass S- 88 stimulator and a SIU5A stimulus isolating unit (Grass Medical Instruments, Quincy, MA) driven by a Master-8 stimulator (A.M.P. Instruments, Jerusalem, Israel). Pulse intensity, duration, and the stimulation pattern were checked before the experiment with an oscilloscope. Slices were fixed $10 \mathrm{~min}$ after the end of the stimulation. To identify the side ipsilateral to the root, a round hole was punched in the ventral horn to mark it.

Electrical stimulation of the dorsal horn. Coronal slices without roots were placed in the slice chamber, held vertically with pins with their dorsal edge up, and superfused as described above. The stimulation electrode (purchased from Frederick Haer, Bowdoinham, ME) was a parallel bipolar hook electrode (1 $\mathrm{mm}$ pole separation, $1 \mathrm{~mm}$ hook diameter) made of platinum/iridium wires $(0.25 \mathrm{~mm}$ thick). The electrode was mounted on a manipulator and brought down on the slice so that its poles were placed on either side of one dorsal horn. The shape and size of the hook electrode was such that it completely covered one of the dorsal horns but not the other. The level of the aCSF flowing through the chamber was lowered until the dorsal funiculus touched the surface, to decrease the short-circuiting of the current between the poles of the electrode above the slice. Electrical stimulation typically consisted of square pulses of $30 \mathrm{~V}$ and $0.4 \mathrm{msec}$ delivered in a single train of 1000 pulses at 100 $\mathrm{Hz}$, but pulse intensity (volts), number of pulses, and frequency were varied in the experiments. Slices were fixed $5 \mathrm{~min}$ after the end of the stimulation. The stimulated side of the slice was marked with a round hole in the ventral horn.

Electrical stimulation of the DLF. Oblique slices were used to stimulate the DLF. Some of these slices were left intact ("no cut"), whereas others were cut transversally between T13 and L1, either across the entire width of the dorsal horn ("DH cut") or across the entire width of the DLF ("DLF cut"). The oblique slices were placed in the slice chamber, held sideways with insect pins with the DLF up, and superfused as described above. The stimulation electrode, the same used to stimulate the dorsal horn, was brought down on the T12 segment of the slice so that its poles were placed on either side of the DLF. Electrical stimulation consisted of square pulses of $20 \mathrm{~V}$ and $0.4 \mathrm{msec}$ delivered in 60 trains of 100 pulses at $100 \mathrm{~Hz}$, one train every $10 \mathrm{sec}$, for a total of 6000 pulses. A few slices were stimulated at lower pulses intensity $(2 \mathrm{~V}, 0.1 \mathrm{msec})$ or at lower frequency $(20 \mathrm{~Hz}$, also in trains of 100 pulses). Slices were fixed $5 \mathrm{~min}$ after the end of the stimulation. To compare MOR internalization at different distances from the stimulation site, fixed slices were cut into three portions: T11-T13 ("rostral"), including the stimulation site and rostral to the cut; L1-L2 ("medial"), just caudal to the cut; and L3-L4 ("caudal"), the most distal to the stimulation site.

Antibodies. To label MORs we used a rabbit antiserum (1:7000 dilu- 
tion) raised against amino acids 384-398 of the cloned rat MOR-1 (DiaSorin, Stillwater, MN; catalog no. 24216). This antiserum has been characterized (Arvidsson et al., 1995) and shown to label dorsal horn neurons (Spike et al., 2002). It does not recognize the MOR-1C and MOR-1D splice variants, but these are present in primary afferent terminals and mostly absent from dorsal horn neurons (Abbadie et al., 2001). To label neurokinin-1 receptor (NK1R), we used NK1R guinea pig antiserum (1:1000 dilution) purchased from Chemicon (Temecula, CA; catalog AB5800), raised against amino acids 393-407 of the rat NK1R, or rabbit antiserum (1:2000 dilution; number 94168) (a gift from Dr. Nigel Bunnett, University of California San Francisco) also raised against amino acids 393-407 of the rat NK1R, previously characterized (Grady et al., 1996). Double labeling with the rabbit NK1R and guinea pig NK1R antisera resulted in complete colocalization of the staining at the cellular and subcellular levels. The guinea pig NK1R antiserum was used for double labeling with the MOR antibody. To label opioid-containing fibers, we used monoclonal antibody 3-E7 (dilution 1:1000) purchased from Gramsch Laboratories (Schwabhausen, Germany), which recognizes the $\mathrm{N}$-terminal sequence Tyr-Gly-Gly-Phe-Met- of $\beta$-endorphin and cross-reacts completely with Met- and Leu-enkephalin and partially with dynorphins and $\alpha$-neoendorphin (Gramsch et al., 1983; Song and Marvizón, 2003). Secondary antibodies were Alexa- 488 goat anti-rabbit IgG and Alexa-568 goat anti-guinea pig IgG, both from Molecular Probes, used at 1:2000 and 1:1000 dilutions, respectively.

Immunohistochemistry. Histological sections from spinal cord slices were routinely double labeled for MORs and NK1Rs to assess the internalization of both receptors. NK1R internalization served to confirm that electrical stimulation had been delivered to the slice when there was no MOR internalization. Sections were prepared and labeled as described previously (Marvizón et al., 1997, 1999a, 2003; Song and Marvizón, 2003), with some modifications. Coronal and oblique slices were fixed, cryoprotected, frozen on dry ice, and sectioned with a cryostat at $25 \mu \mathrm{m}$ in the coronal or oblique planes, respectively. For oblique slices, only the topmost 16 sections (corresponding to the dorsal horn) were collected. Sections were washed twice with PBS and twice with PBS, 0.3\% Triton $\mathrm{X}-100,0.001 \%$ thimerosal (PBS/Triton) containing 5\% normal goat serum and then incubated at room temperature overnight with the MOR and NK1R primary antibodies in PBS/Triton. For double labeling, the rabbit MOR and guinea pig NK1R antisera were added together to the sections. After three washes with PBS, sections were incubated for $2 \mathrm{hr}$ at room temperature with the secondary antibodies (combined for double labeling) in PBS/Triton. Sections were washed four more times with PBS and mounted in Prolong. Preabsorption of the MOR antibody with its immunizing peptide $(10 \mu \mathrm{g} / \mathrm{ml})$ abolished the staining. Labeling of MOR in sections from slices was similar to sections from perfusion-fixed rats (Marvizón et al., 1999a). A similar procedure was used to label spinal cord sections with the 3E7 antibody: adult rats were anesthetized with isoflurane and fixed by aortal perfusion; a lumbar segment of the spinal cord was sectioned in the horizontal plane at the level of the DLF, and sections were incubated with the 3E7 antibody (other details were the same as above).

Confocal microscopy and image processing. Confocal images were acquired at the Carol Moss Spivak Cell Imaging Facility of the University of California Los Angeles with a Leica TCS-SP confocal microscope outfitted with argon (476 and $488 \mathrm{~nm}$ ) and krypton $(568 \mathrm{~nm})$ lasers. The pinhole was 1.0 Airy units. Objectives were $20 \times(0.7$ numerical aperture), $63 \times(1.32$ numerical aperture $)$ or $100 \times(1.4$ numerical aperture $)$, giving optical section thickness (full-width half-maximum) of 2.53, 0.69, and $0.62 \mu \mathrm{m}$, respectively. Optical sections were obtained at intervals of $2.48 \mu \mathrm{m}$ (for $20 \times$ ) or $0.57 \mu \mathrm{m}$ (for $63 \times$ and $100 \times$ ) and averaged four times to reduce noise. Images were processed using Adobe Photoshop 5.5. The "curves" feature of the program was used to adjust the contrast and balance the colors of double-labeled images. Images were acquired at a digital size of $1024 \times 1024$ pixels and were later cropped to the relevant part of the field without altering the original image resolution.

Quantification of MOR and NK1R internalization. Previously described procedures were used to quantify MOR internalization (Marvizón et al., 1999a; Song and Marvizón, 2003) and NK1R internalization (Mantyh et al., 1995; Abbadie et al., 1997; Marvizon et al., 1997, 1999b,
2003; Trafton et al., 1999, 2001). The person counting the neurons was blinded to the treatment given to the slice. A Zeiss Axiovert 135 (Carl Zeiss, Thornwood, NY) fluorescence microscope outfitted with a $100 \times$ objective was used to count neurons. The percentage of MOR neurons in laminas I-II or NK1R neurons in lamina I with internalization was calculated in relation to the total number of MOR or NK1R neurons sampled, respectively. MOR neuronal somas with $>5$ endosomes and NK1R somas with $>10$ endosomes were considered to have internalized receptors. At least three sections per slice were counted.

Data analysis. Treatments were randomized between slices, and no more than two slices from the same animal received the same treatment. Data were analyzed using Prism 4 (GraphPad Software, San Diego, CA). Error bars represent SE. Statistical analyses consisted of one-way ANOVA and Tukey's post-test, or two-way ANOVA and Bonferroni's post-test, with significance set at 0.05 . Some data were fitted using nonlinear regression by a saturation function: $Y=B_{\max }{ }^{*} X /\left(K_{\mathrm{D}}+X\right)$ or by a sigmoidal dose-response function: $Y=$ bottom + (top-bottom) $/(1+$ $\left.10^{\wedge}\left(\log \mathrm{EC}_{50}-\log \mathrm{X}\right)\right)$, where "top" and "bottom" are the maximum and minimum values of $Y$, respectively, and $\mathrm{EC}_{50}$ is the value of $X$ that produces half of the response $(Y)$. Parameter constraints were $0 \%<$ top $<100 \%, 0 \%<$ bottom. The statistical error associated with the $\mathrm{EC}_{50}$ was expressed as $95 \%$ confidence interval (95\% C.I.).

\section{Results}

We found previously that MOR internalization in the dorsal horn produced by released opioids could be assessed only in the presence of inhibitors of three peptidases (Song and Marvizón, 2003). Therefore, unless stated otherwise, all experiments were done in the presence of phosphoramidon, an inhibitor of neutral endopeptidase (EC.3.4.24.11), captopril, an inhibitor of dipeptidyl carboxypeptidase (EC.3.4.15.1), and amastatin or actinonin, inhibitors of aminopeptidase N (EC.3.4.11.7).

\section{Dorsal root stimulation}

Our first goal was to determine whether opioids are released from primary afferents. To achieve this, we stimulated electrically one dorsal root attached to a coronal spinal cord slice and measured MOR internalization and NK1R internalization in the ipsilateral and contralateral dorsal horns. NK1R internalization was measured to determine whether endomorphins (or other opioids) are co-released with neurokinins from primary afferent terminals, as suggested by previous studies (Martin-Schild et al., 1998; Pierce et al., 1998; Williams et al., 1999). Slices were superfused with aCSF at $35^{\circ} \mathrm{C}$ containing peptidase inhibitors, and the root was placed on a bipolar electrode and covered with mineral oil in a side compartment of the slice chamber. This method provides very consistent stimulation because the electric current is forced to pass through the root by the low conductivity of the mineral oil, and it also prevents the current from reaching the dorsal horn and directly evoking peptide release there. Electrical stimulation consisted of 6000 pulses of $30 \mathrm{~V}$ and $0.4 \mathrm{msec}$. This pulse intensity and duration were sufficient to recruit C-fibers (Koslow et al., 1973; Li and Bak, 1976; Swett and Bourassa, 1981) because (1) it produced NK1R internalization (Fig. 1), (2) higher pulse intensities did not produce more NK1R internalization (data not shown), and (3) it evoked action potentials with C-fiber conduction velocity when used to stimulate the sciatic nerve of anesthetized rats in similar conditions (i.e., in a pool of mineral oil) (Marvizón et al., 2000).

The pattern of primary afferent firing plays a crucial role in determining the release of different neuropeptides. Thus, substance P release (Go and Yaksh, 1987) and NK1R internalization (Marvizón et al., 1997, 2000) are favored by high-frequency stimulation, whereas the release of brain-derived neurotrophic factor (BDNF) can be elicited only by a firing pattern consisting of short 


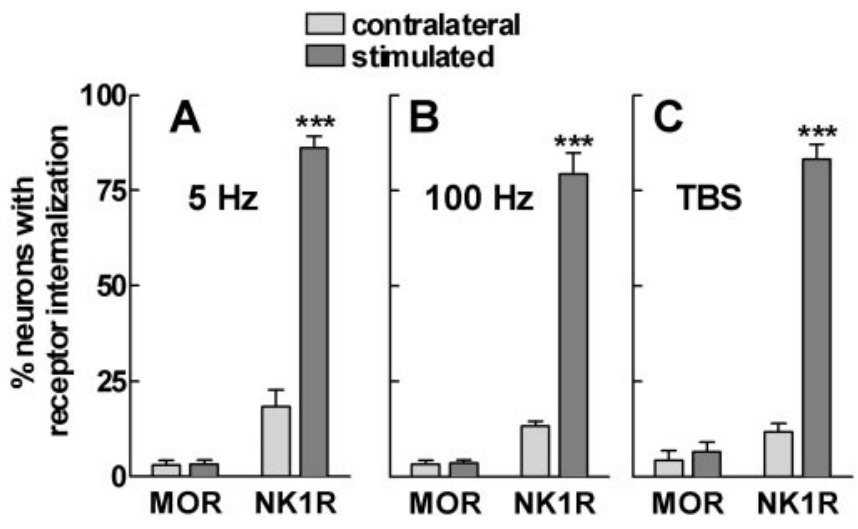

Figure 1. Dorsal root stimulation. Coronal spinal cord slices with one dorsal root were placed in a slice chamber and superfused with aCSF containing peptidase inhibitors for at least 2 min before stimulation. The root was drawn into a side compartment, placed on a bipolar electrode, and covered with mineral oil. Electrical stimulation consisted of 6000 pulses of $30 \mathrm{~V}$ and 0.4 msec delivered in three different patterns: single train at $5 \mathrm{~Hz}$ for $20 \mathrm{~min}(A) ; 60$ trains of 100 pulses at $100 \mathrm{~Hz}$ every $10 \mathrm{sec}(B) ; 1500$ trains of 4 pulses at $100 \mathrm{~Hz}$ every $0.2 \mathrm{sec}$ (TBS) (C). MOR and NK1R internalization were measured in laminas I-II and lamina I, respectively, of the dorsa horn ipsilateral (stimulated) or contralateral to the root. Data are the mean $\pm \mathrm{SEM}$ of four slices ( 5 slices in $B$ ). Each panel was analyzed with a two-way ANOVA, the two variables being side (stimulated or contralateral) and receptor (MOR or NK1R). The effect of both variables and their interaction was significant $(p<0.0001)$ for $A-C$. Bonferroni's post-test revealed significant differences between the stimulated and contralateral sides for NK1R $\left({ }^{* * *} p<0.001\right)$ but not for MOR.

bursts at high frequency (Lever et al., 2001). Therefore, we used three different root stimulation patterns to evoke opioid release. The first (Fig. 1A) was a continuous train at low frequency $(5 \mathrm{~Hz}$ for $20 \mathrm{~min}$ ). We did not use lower frequencies to be able to deliver a large number of pulses in a sufficiently short period of time. The second stimulation pattern (Fig. $1 B$ ) consisted of high-frequency stimulation $(100 \mathrm{~Hz})$. Because C-fibers may be unable to follow long periods of high-frequency stimulation (Swett and Bourassa, 1981), the 6000 pulses were distributed in 60 trains of 100 pulses each, 1 train every $10 \mathrm{sec}$. The third stimulation pattern (Fig. 1C) was the one that evokes BDNF release [theta burst stimulation (TBS)]: short trains ("bursts") of four pulses at $100 \mathrm{~Hz}$, one train delivered every $0.2 \mathrm{sec}$.

All three stimulation patterns produced abundant NK1R internalization but negligible MOR internalization, as can be observed in the confocal images in Figure $2 B-D$. In contrast, little NK1R internalization was found in the nonstimulated (contralateral) side of the slices (Fig. $2 \mathrm{~A}$ ); the amount of NK1R internalization in it (Fig. 1) was similar to that obtained in control (not stimulated) slices (Marvizón et al., 1997). Confirming a previous report (Spike et al., 2002), we found absolutely no colocalization of MOR and NK1R immunoreactivities in the dorsal horn (Figs. $2,3)$. Quantitative data corresponding to each of the three stimulation patterns (Fig. 1) were analyzed with a two-way ANOVA with the variables "side" (i.e., ipsilateral versus contralateral) and "receptor" (MOR or NK1R). The effect of both variables and their interaction was significant $(p<0.0001)$ for all three patterns. Bonferroni's post-test revealed significant differences between the stimulated and contralateral sides for NK1R $(p<$ 0.001 ) but not for MOR. Although NK1R neurons are located in lamina I and MOR neurons are more abundant in lamina II (Fig. $2 A, C$ ), occasionally they were observed in close proximity (Fig. $2 B)$, but the differences in internalization persisted, indicating that the lack of MOR internalization was not caused by the inability of released opioids to diffuse into lamina II. Root stimulation produced NK1R internalization in lamina III neurons as well
(Fig. 2D) and thus was able to release an amount of neurokinins sufficient to diffuse into this lamina. In conclusion, dorsal root stimulation able to produce abundant neurokinin release did not produce enough opioid release to activate MORs in dorsal horn neurons.

\section{Lack of effect of capsaicin and NMDA on MOR internalization}

To further explore whether opioids are released from primary afferents, we incubated spinal cord slices with compounds known to stimulate neurokinin release (Table 1). Capsaicin produces abundant substance P release (Go and Yaksh, 1987; Aimone and Yaksh, 1989; Afrah et al., 2001; Lever and Malcangio, 2002) and subsequent NK1R internalization (Lao et al., 2003; Marvizón et al., 2003), but it failed to produce MOR internalization at a concentration of $10 \mu \mathrm{M}$. Likewise, NMDA produces NK1R internalization (Marvizón et al., 1997) and substance P release (Malcangio et al., 1998) by activating presynaptic NMDA receptors expressed in primary afferent neurons (Marvizón et al., 2002) and present in the central terminals of C-fibers (Liu et al., 1994). NMDA $(100 \mu \mathrm{M})$ also failed to elicit MOR internalization, although it was applied together with D-serine $(10 \mu \mathrm{M})$, a specific agonist of the glycine coagonist site of NMDA receptors, which is required for their activation (Johnson and Ascher, 1987). To avoid excitotoxic effects, the incubation time with NMDA plus D-serine was kept short $(1 \mathrm{~min})$ and was followed by a $10 \mathrm{~min}$ incubation with peptidase inhibitors to allow enough time for MOR internalization to take place (Marvizón et al., 1999a). Longer incubation times ( $5 \mathrm{~min}$ ) with NMDA also failed to produce MOR internalization. Capsaicin or NMDA plus D-serine also failed to produce MOR internalization in the absence of peptidase inhibitors (data not shown). Therefore, chemical stimuli that produce neurokinin release from primary afferents do not release opioids in amounts sufficient to activate MORs in dorsal horn neurons. Furthermore, we concluded that activation of postsynaptic NMDA receptors in dorsal horn neurons (Randic et al., 1993) does not evoke opioid release either.

\section{Dorsal horn stimulation}

Our second goal was to determine whether electrical stimulation of the dorsal horn could evoke opioid release and MOR internalization. Coronal spinal cord slices were placed with the dorsal horn up in a slice chamber and superfused with peptidase inhibitors. A bipolar electrode was then placed with its poles on either side of one of the dorsal horns. The "hook" shape of the electrode covered practically all of that dorsal horn ("stimulated") but not the other dorsal horn ("contralateral"). We labeled the tissue for NK1Rs in addition to MORs (Fig. 3) to compare the ability of the stimuli to produce neurokinin and opioid release.

First we determined the optimal pulse intensity to evoke opioid release (Fig. 4A). A single train of 1000 pulses at $100 \mathrm{~Hz}$ was delivered through the electrode. Square pulses had a duration of $0.4 \mathrm{msec}$ and intensities between 10 and $70 \mathrm{~V}$ (no current was passed to obtain data at " $0 \mathrm{~V}$ "). In the stimulated dorsal horn, MOR internalization quickly reached a maximum, becoming essentially constant at pulse intensities $>20 \mathrm{~V}$. A saturation function fit well the data points, yielding a $B_{\max }$ of $64 \pm 6 \% \mathrm{MOR}$ neurons with internalization and a $K_{\mathrm{D}}$ of $7 \pm 3 \mathrm{~V}$. In the contralateral dorsal horn, MOR internalization was much lower, becoming appreciable only at the highest pulse intensities. NK1R internalization (Fig. $4 B$ ) increased with pulse intensity in a way similar to that of MOR internalization in the stimulated dorsal horn $\left(B_{\max }=59 \pm 3 \%\right.$ NK1R neurons with internalization; $K_{\mathrm{D}}=$ 

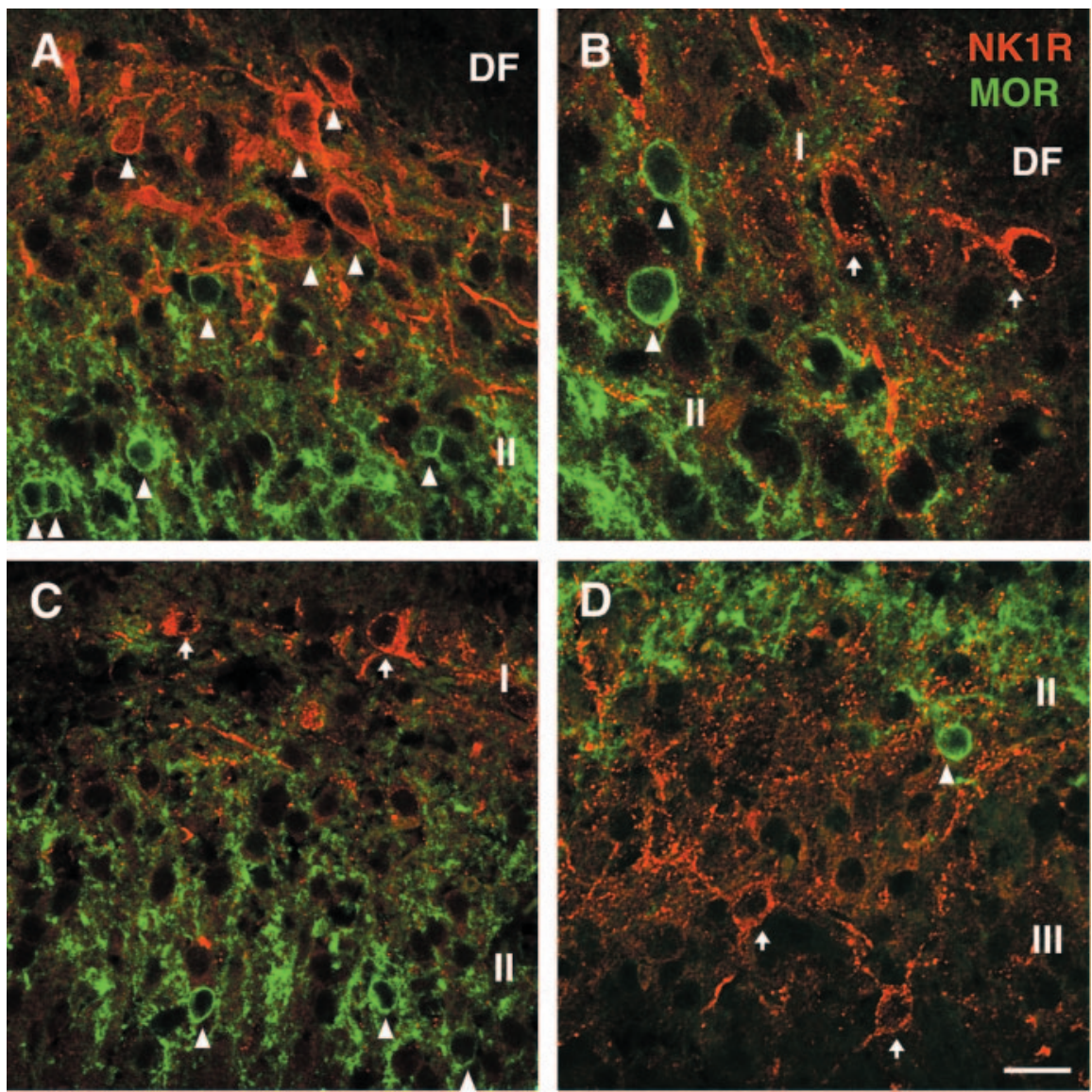

Figure 2. Confocal images of MOR and NK1R neurons after dorsal root stimulation. Coronal spinal cord slices were superfused with peptidase inhibitors and stimulated at the dorsal root with 6000 pulses delivered at $5 \mathrm{~Hz}$ continuously, at $100 \mathrm{~Hz}$ in 60 trains, or as TBS (trains every $0.2 \mathrm{sec}$ of 4 pulses at $100 \mathrm{~Hz}$ ). Sections from the slices were double labeled for MOR (green) and NK1R (red). Dorsal is up. Roman numerals indicate the approximate position of laminas I-III. DF, Dorsal funiculus. Arrows and arrowheads indicate cells with and without internalization, respectively. $A$, No stimulation (contralateral to the root stimulated with TBS): five NK1R neurons and five MOR neurons in the central dorsal horn show no internalization. B, Stimulation at $5 \mathrm{~Hz}$ : two NK1R neurons in the medial dorsal horn show substantial internalization, whereas two MOR neurons show no internalization. C, Stimulation at $100 \mathrm{~Hz}$ : two NK1R neurons in lamina I of the central dorsal horn show abundant internalization, whereas three MOR neurons in lamina II show no internalization. D, Stimulation with TBS: two NK1R neurons in lamina III of the central dorsal horn show internalization, whereas a MOR neuron in lamina II shows no internalization. Confocal images were taken at $63 \times$ for $A, C$, and $D$ (scale bar, $20 \mu \mathrm{m}$ ) and at $100 \times$ for $B$ (scale bar, $12.5 \mu \mathrm{m}$ ) and consist of two optical sections separated $0.57 \mu \mathrm{m}$.

$6 \pm 2 \mathrm{~V})$ but was higher in the contralateral dorsal horn. The presence of MOR and NK1R internalization in the contralateral dorsal horn indicated that some of the electrical current spread into it; however, its effect was indistinguishable from controls at intensities $<30 \mathrm{~V}$. Because $30 \mathrm{~V}$ produced maximal internalization in the stimulated dorsal horn, it was chosen as the standard pulse intensity for subsequent experiments.

Second, we investigated the effect of the number of pulses on MOR internalization. Pulses of $30 \mathrm{~V}$ and $0.4 \mathrm{msec}$ were delivered at $100 \mathrm{~Hz}$ in a single train. MOR internalization increased with the number of pulses, also following a saturation curve; however, we represented the data in Figure $5 A$ in a logarithmic scale for clarity, fitting them to a sigmoidal dose-response curve. The fitting yielded an $\mathrm{EC}_{50}$ of 131 pulses (95\% C.I. $=28-606$ pulses) and a maximum effect ("top") of $63 \pm 4 \%$ MOR neurons with internalization. Therefore, even a large number of pulses did not produce MOR internalization in all MOR neurons of the stimulated dorsal horn. Similarly, NK1R internalization (Fig. 5B) saturated with increasing the number of pulses, with a maximum effect of $62 \pm 2 \%$ NK1R neurons and an $\mathrm{EC}_{50}$ of 237 pulses $(95 \%$
C.I. $=118-479$ pulses). A large number of pulses also produced substantial MOR and NK1R in the contralateral dorsal horn, showing that the efficiency of the residual current spreading into this dorsal horn increased with the number of pulses.

Third, we studied the effect of stimulation frequency on MOR internalization. One thousand pulses of $30 \mathrm{~V}$ and $0.4 \mathrm{msec}$ were delivered in a single train at frequencies between 1 and $100 \mathrm{~Hz}$. MOR internalization increased dramatically with stimulation frequency (Fig. 6A). At frequencies $<10 \mathrm{~Hz}$, MOR internalization was negligible, whereas NK1R internalization was observed in many neurons (Fig. 6B). For example, Figure $3 A$ shows an area in the central dorsal horn after $3 \mathrm{~Hz}$ stimulation: no internalization is observed in the MOR neuron in the center of the image, but substantial internalization can be seen in several NK1R neurons surrounding it. Likewise, no MOR internalization was observed in slices not stimulated (Fig. 7A). At frequencies $>10 \mathrm{~Hz}$ the number of MOR neurons with internalization increased dramatically, following a saturation function. Data in Figure $6 \mathrm{~A}$ were fitted with a sigmoidal dose-response function (because they were plotted using a logarithmic scale), which yielded a maximum effect of $84 \pm 7 \%$ MOR neurons and an $\mathrm{EC}_{50}$ of $53 \mathrm{~Hz}$ (95\% C.I. $=19-144$ $\mathrm{Hz}$ ). Figure $7 B$ shows two MOR neurons with internalization after $100 \mathrm{~Hz}$ stimulation, and Figures $3 B$ and $7 C$ show neurons with MOR internalization after $500 \mathrm{~Hz}$ stimulation in the medial and central dorsal horn, respectively. One neuron in Figure $3 B$ also shows NK1R internalization. Therefore, very high stimulation frequencies $(500 \mathrm{~Hz})$ produced MOR internalization in most MOR dorsal horn neurons; however, in the absence of peptidase inhibitors, even $500 \mathrm{~Hz}$ stimulation did not produce MOR internalization (just in $4 \pm 2 \%$ of MOR neurons of the stimulated dorsal horn), but it still produced NK1R internalization (in $52 \pm 1 \%$ of NK1R neurons of the stimulated dorsal horn).

In these conditions, NK1R internalization showed little frequency dependence, in contrast with our previous results using dorsal root stimulation (Marvizón et al., 1997, 1999b). Thus, two-way ANOVA of the data in Figure $6 B$ yielded no significant effect of frequency; however, there was a trend toward an increase of NK1R internalization with frequency up to $200 \mathrm{~Hz}$ and then a decrease at $500 \mathrm{~Hz}$ (probably because the stimulated fibers could not follow this high frequency). In a parallel study (our unpublished observations), we found that the frequency dependence of NK1R internalization becomes less pronounced in the presence of peptidase inhibitors, which explains these results.

Fourth, we confirmed that MOR internalization produced by electrical stimulation of the dorsal horn was caused by opioid release. Coronal slices were stimulated with 3000 pulses ( $30 \mathrm{~V}$ and $0.4 \mathrm{msec}$ ) at $100 \mathrm{~Hz}$ while they were superfused with peptidase 

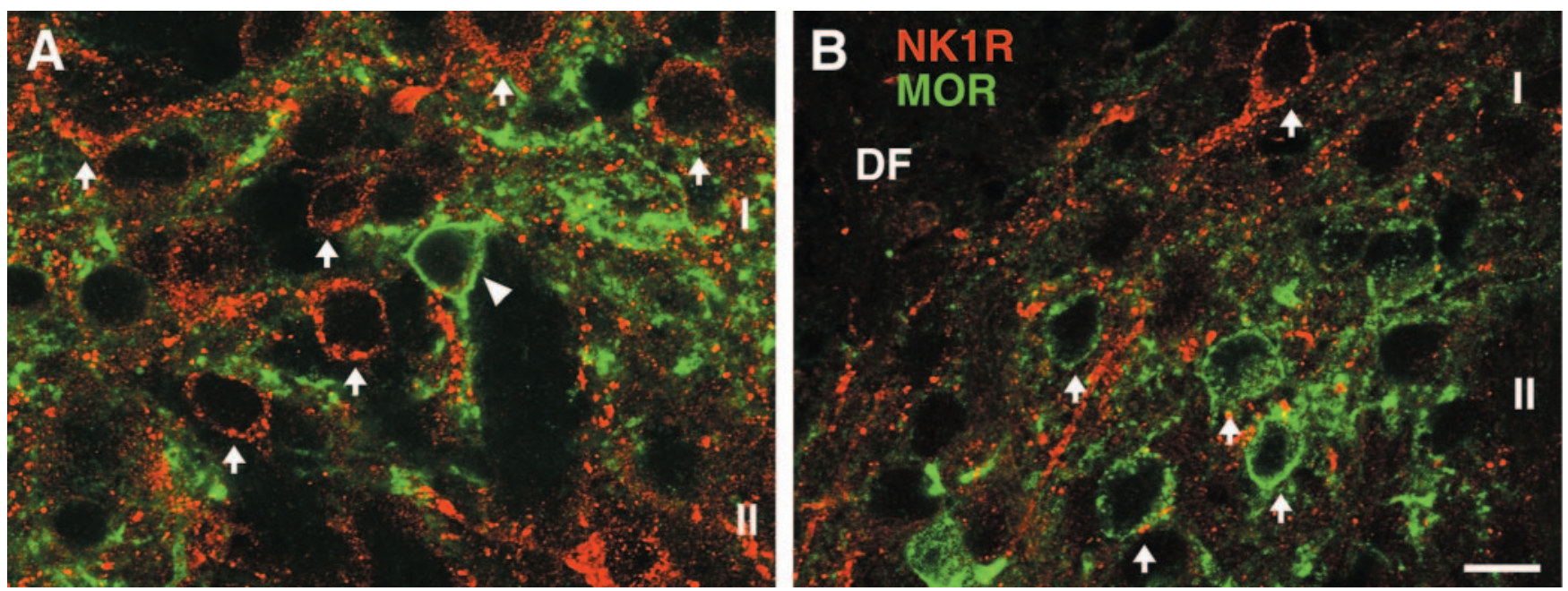

Figure 3. Confocal images of MOR and NK1R neurons after dorsal horn stimulation. Coronal spinal cord slices were superfused with peptidase inhibitors, and one dorsal horn was stimulated with a single train of 1000 pulses. Dorsal is up. Roman numerals indicate the approximate position of laminas I and II. DF, Dorsal funiculus. Arrows and arrowheads indicate cells with and without internalization, respectively. A, Stimulation at $3 \mathrm{~Hz}$ produced abundant NK1 R internalization in this cluster of NK1R neurons, but no MOR internalization in the MOR neuron in the center of the image. $B$, Stimulation at $500 \mathrm{~Hz}$ produced MOR internalization in this cluster of MOR neurons and NK1R internalization in the neuron at the top of the image. Confocal images were taken at $100 \times$ (scale bar, $10 \mu \mathrm{m})$ and consist of two optical sections separated $0.57 \mu \mathrm{m}$.

Table 1. Lack of effect of capsaicin and NMDA on MOR internalization

\begin{tabular}{|c|c|c|c|c|c|}
\hline Drugs & Drug concentration & Incubation with drug & Incubation without drug & \% MOR neurons with internalization & $n$ \\
\hline None & & & $20 \mathrm{~min}$ & $11 \pm 1$ & 10 \\
\hline Capsaicin & $10 \mu \mathrm{M}$ & $20 \mathrm{~min}$ & 0 min & $12 \pm 3$ & 4 \\
\hline NMDA, D-Ser & $100 \mu \mathrm{M}, 10 \mu \mathrm{M}$ & $1 \mathrm{~min}$ & $10 \mathrm{~min}$ & $8 \pm 2$ & 4 \\
\hline
\end{tabular}

Coronal spinal cord slices were incubated at $35^{\circ} \mathrm{C}$ in aCSF containing peptidase inhibitors (amastatin, captopril, and phosphoramidon) and the drugs indicated. Data are the mean \pm SE of $n$ slices. ANOVA indicated no significant differences from "None" ( $p=0.35)$.

inhibitors and other additions (Table 2). The MOR-selective antagonist D-Phe-Cys-Tyr-D-Trp-Arg-Thr-Pen-Thr- $\mathrm{NH}_{2}$ (CTAP) $(10 \mu \mathrm{M})$ abolished MOR internalization produced by dorsal horn stimulation (Fig. 7D), showing that it was caused by the binding of agonists to the receptor. MOR internalization was also abolished in aCSF that contained a lower concentration of $\mathrm{Ca}^{2+}(0.2$ $\mathrm{mm}$ instead of $2.4 \mathrm{~mm}$ ) (Fig. $7 E$ ), probably because this prevented the $\mathrm{Ca}^{2+}$-dependent release of opioids. This low concentration of $\mathrm{Ca}^{2+}$ did not interfere with MOR internalization produced by exogenously added opioids (Song and Marvizón, 2003). Finally, MOR internalization was abolished by $1 \mathrm{~mm}$ lidocaine (Fig. $7 F$ ), $\mathrm{a} \mathrm{Na}^{+}$channel blocker that prevents the firing of action potentials (Courtney and Strichartz, 1987). Therefore, the electrical pulses produced opioid release by evoking action potentials and not by directly depolarizing presynaptic terminals.

\section{DLF stimulation}

Our third goal was to investigate whether electrical stimulation of the DLF was able to produce opioid release in the dorsal horn. The DLF contains axons of neurons in the ventromedial medulla projecting into the dorsal horn (Basbaum et al., 1976; Basbaum and Fields, 1979, 1984) that produce MOR-mediated analgesia, probably through the release of opioids from dorsal horn interneurons (Todd and Spike, 1993; Budai and Fields, 1998). In coronal spinal cord sections, we observed that the DLF was brightly labeled by the monoclonal antibody 3E-7 (Song and Marvizón, 2003), which recognizes endorphins, enkephalins, and dynorphins. We now labeled horizontal spinal cord sections at the level of the DLF with the $3 \mathrm{E}-7$ antibody to determine the morphology of the 3-E7-immunoreactive structures. As can be observed in Figure $8 \mathrm{~A}$, the $3 \mathrm{E}-7$ antibody stained numerous fibers in the DLF running rostrocaudally. A few lateral branches and puncta were observed at higher magnification (Fig. $8 \mathrm{~B}$ ). Therefore, axons in the DLF contain opioids and may release them when stimulated.

Because DLF axons course rostrocaudally and branch gradually into the dorsal horn (Fields et al., 1995), in coronal spinal cord slices there would be very little fiber continuity between the DLF and the dorsal horn. Therefore, stimulating the DLF in coronal slices would not allow us to detect opioid release in the dorsal horn. This experiment required a slice preparation that (1) contained both the dorsal horn and the DLF, (2) extended rostrocaudally for several spinal segments, and (3) was thin enough to allow oxygen penetration for cell survival. To meet these requirements, we developed an oblique spinal cord slice preparation that was cut at a $45^{\circ}$ angle between the horizontal and the sagittal planes to comprise most of the DLF and the dorsal horn throughout spinal segments T11-L4 (see Materials and Methods).

Oblique slices were superfused with peptidase inhibitors, and a bipolar electrode was placed on either side of the DLF at the rostral end of the slice (T12) to evoke action potentials in DLF axons that would travel anterogradely and enter the dorsal horn for the entire length of the slice. We also expected some retrograde propagation of action potentials into T11. Control slices were treated the same way, including superfusion with peptidase inhibitors and electrode placement, but no current was passed. Stimulation consisted of square pulses of $20 \mathrm{~V}$ and $0.4 \mathrm{msec}$ delivered at $100 \mathrm{~Hz}$. A large number of pulses (6000) were used but broken into 60 trains of 100 pulses ( 1 train every $10 \mathrm{sec}$ ) to prevent the blockade of fibers that might be unable to follow highfrequency stimulation. Some slices were stimulated similarly but with lower pulse intensity $(2 \mathrm{~V}, 0.1 \mathrm{msec})$ or at lower frequency 

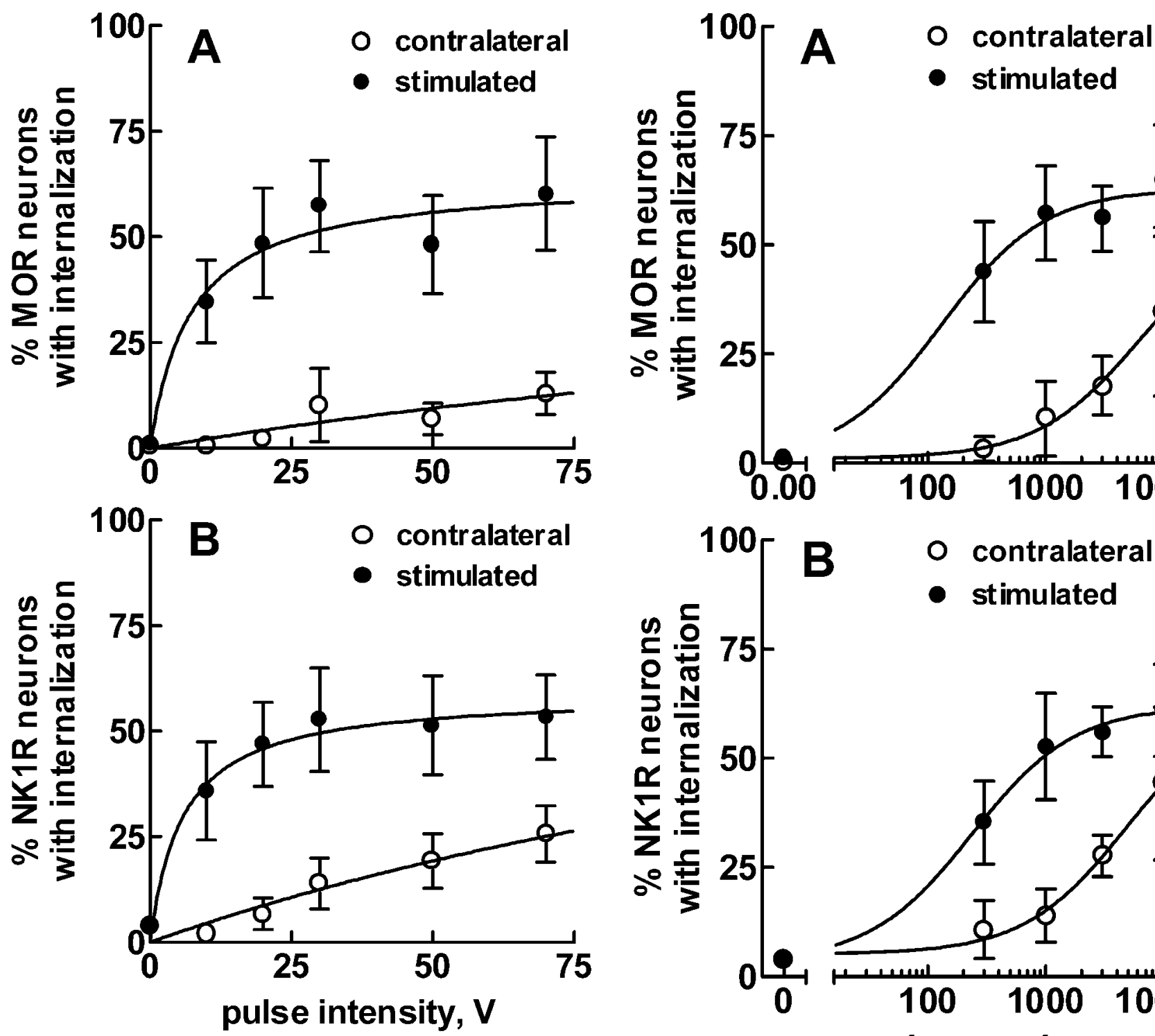

Figure 4. Dorsal horn stimulation: pulse intensity. Coronal spinal cord slices were superfused with aCSF containing peptidase inhibitors. A hook stimulation electrode was positioned with its poles on either side of one of the dorsal horns (stimulated) and used to deliver 1000 pulses in a single train at $100 \mathrm{~Hz}$. Pulses had a duration of $0.4 \mathrm{msec}$ and intensities of $10-70 \mathrm{~V}$, as indicated in the figure. For $\mathrm{V}$, slices were treated in the same way, but no current was passed through the electrode. Sections from the slices were double labeled for MOR and NK1R, and internalization of MOR in laminas I-II neurons $(A)$ and NK1R in lamina I neurons $(B)$ was measured in the same sections. Points represent the mean \pm SEM of four to six slices. Two-way ANOVA for each panel revealed significant effects of side (i.e., stimulated versus contralateral; $p<0.0001$ ) and pulse intensity $(p<0.01)$. Curves represent fitting of a saturation function to the data, yielding the following parameter values: $\mathrm{MOR}$, stimulated side: $B_{\max }=64 \pm 6 \% \mathrm{MOR}$ neurons, $K_{\mathrm{D}}=7 \pm$ $3 \mathrm{~V}$; NK1R, stimulated side: $B_{\max }=59 \pm 3 \%$ NK1R neurons, $K_{D}=6 \pm 2 \mathrm{~V}$.

(20 Hz), but this did not produce MOR internalization, even near the electrode (data not shown).

Because axons from the RVM innervate the dorsal horn along the entire length of the spinal cord (Fields et al., 1995), their firing should produce opioid release in areas distant from the stimulation site. Therefore, we compared MOR internalization at different distances from the stimulation site by dividing the oblique slices into three portions comprising segments T11-T13 (rostral, encompassing the stimulation site), L1-L2 (medial), and L3-L4 (caudal). Each portion was then sectioned at $25 \mu \mathrm{m}$ and double

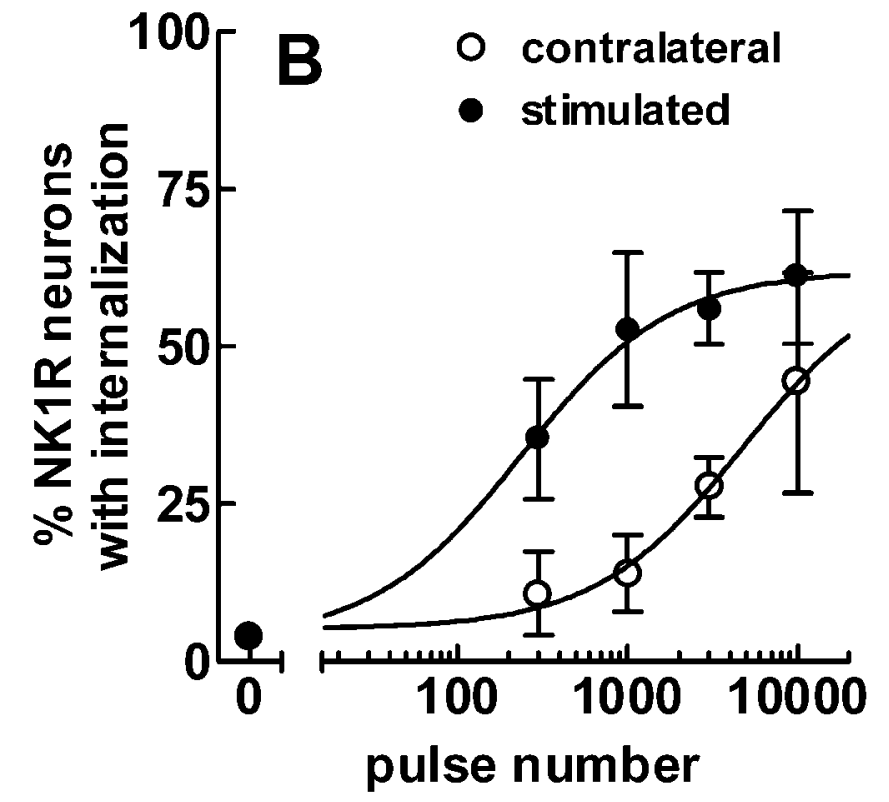

Figure 5. Dorsal horn stimulation: number of pulses. Coronal spinal cord slices were superfused with aCSF containing peptidase inhibitors. The stimulation electrode was positioned with its poles on either side of one of the dorsal horns (stimulated) and used to deliver a single train at $100 \mathrm{~Hz}$ with the indicated number of pulses $(30 \mathrm{~V}, 0.4 \mathrm{msec}$ ). For 0 pulses, no current was passed through the electrode (same data as $0 \mathrm{~V}$ in Fig. 4). Sections from the slices were double labeled for MOR and NK1R, and internalization of MOR in laminas I-II neurons $(A)$ and NK1R in lamina I neurons $(B)$ was measured in the same sections. Points represent the mean \pm SEM of three to six slices. Two-way ANOVA for each panel revealed significant effects $(p<0.001)$ of side (i.e., stimulated versus contralateral) and pulse number. Curves represent fitting of a sigmoidal dose-response function to the data, yielding the following parameter values: MOR, stimulated side: top $=63 \pm 4 \%$ MOR neurons, $\mathrm{EC}_{50}=131$ pulses $(95 \%$ C.I. $=28-606$ pulses); NK1R, stimulated side: top $=62 \pm 2 \%$ NK1R neurons, $\mathrm{EC}_{50}=237$ pulses ( $95 \%$ C.I. $=$ $118-479$ pulses).

labeled for MORs and NK1Rs. We measured NK1R internalization to have positive control of the efficiency of the stimulation.

Results are shown in Figure 9 and in confocal images of the medial portion of the slices (Fig. 10). In control slices, MOR internalization was negligible (Figs. 9A, 10A) and NK1R internalization (Figs. 9B, 10A) was at background level (Fig. 1). DLF stimulation in intact slices (no cut) produced a substantial increase of both MOR internalization and NK1R internalization in 

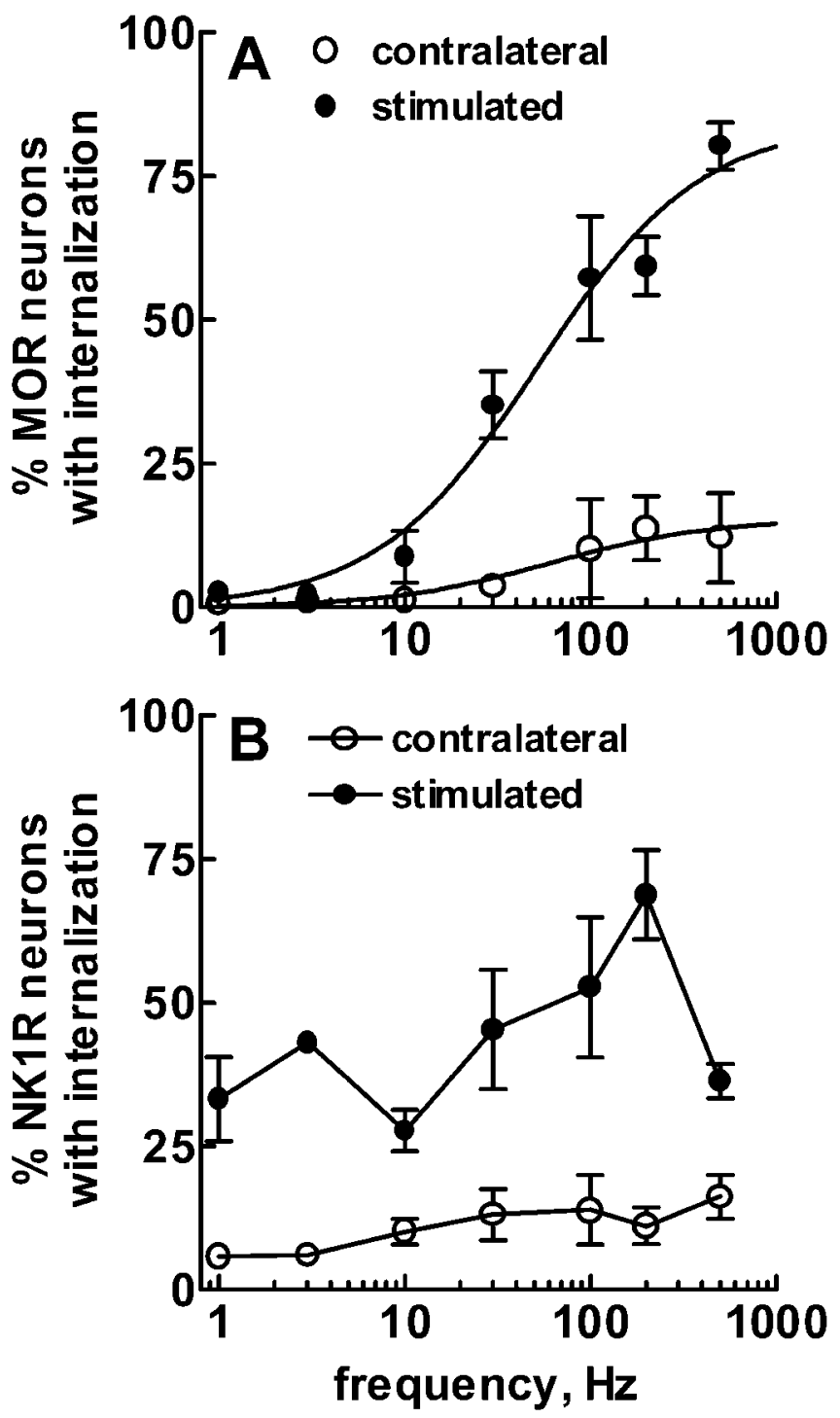

Figure 6. Dorsal horn stimulation: frequency. Coronal spinal cord slices were superfused with aCSF containing peptidase inhibitors. The stimulation electrode was positioned with its poles on either side of one of the dorsal horns (stimulated) and used to deliver a single train of 1000 pulses $(30 \mathrm{~V}, 0.4 \mathrm{msec}$ ) at the indicated frequencies. Sections from the slices were double labeled for MOR and NK1R, and internalization of MOR in laminas I-II neurons $(A)$ and NK1R in lamina I neurons $(B)$ was measured in the same sections. Points represent the mean $\pm S E M$ of three to six slices. Two-way ANOVA of the MOR internalization data revealed significant effects $(p<0.0001)$ of side (i.e., stimulated versus contralateral) and frequency and their interaction. Two-way ANOVA of the NK1R internalization data revealed a significant effects of side ( $p<$ 0.0001 ) but not of frequency. Curves represent fitting of a sigmoidal dose-response function, yielding the following parameter values for MOR (stimulated side): top $=84 \pm 7 \% \mathrm{MOR}$ neurons, $\mathrm{EC}_{50}=53 \mathrm{~Hz}(95 \%$ C.I. $=19-144 \mathrm{~Hz})$.

the rostral and medial portions (Fig. $10 \mathrm{~B}$ ), but not in the caudal portion, suggesting that the signals producing opioid and neurokinin release were not able to travel far down the DLF axons. In fact, they may have traveled via the dorsal horn because although the stimulation electrode was placed around the DLF, some of the electric current may have spread to the adjacent dorsal horn, producing opioid release from the axons of interneurons extending away from the stimulation site. To examine this possibility, we cut the oblique slices transversally between T13 and L1, just caudal of the stimulation site at T12. One set of slices was cut across the entire width of the dorsal horn (DH cut), leaving the DLF intact, to allow action potentials to travel from the rostral to the medial portion only through the DLF. Conversely, another set of slices was cut across the DLF (DLF cut), leaving the dorsal horn intact, to allow action potentials to travel from the rostral to the medial portion only through the dorsal horn. Slices with the DH cut showed a significant $(p<0.05)$ (Fig. 9) decrease in both MOR and NK1R internalization in their medial portion (Fig. $10 C)$ compared with intact slices and, surprisingly, even a trend toward a decrease in the rostral portion. Therefore, exclusive stimulation of the DLF was not able to evoke opioid release. In contrast, in slices with the DLF cut, MOR and NK1R internalization in the medial portion (Fig. $10 \mathrm{D}$ ) was not significantly different from intact slices. Therefore, results in intact slices (no cut) are attributable to action potentials traveling via the dorsal horn and not via the DLF.

Stimulation of the DLF in the presence of $\mathrm{GABA}_{\mathrm{A}}$ and glycine antagonists

One possible explanation for the failure of DLF stimulation to induce opioid release in the dorsal horn is that the stimulus recruited fibers that inhibit opioid release together with those that stimulate it. We further hypothesized that this inhibition of opioid release was mediated by a GABAergic action similar to the one that mediates the mutual inhibition between ON cells and OFF cells in the nucleus raphe magnus (Fields et al., 1991; Skinner et al., 1997). GABAergic interneurons are abundant in the dorsal horn (Todd and McKenzie, 1989; Powell and Todd, 1992; Laing et al., 1994), and many of them are also glycinergic (Todd and Sullivan, 1990; Todd et al., 1996). Thus, to test this hypothesis, we superfused oblique slices with the $\mathrm{GABA}_{\mathrm{A}}$ antagonist (-)bicuculline methbromide $(5 \mu \mathrm{M})$ and the glycine antagonist strychnine $(2 \mu \mathrm{M})$ and stimulated their DLF at T12. The slices were cut across the dorsal horn at T13 to ensure that action potentials propagating caudally had to travel through the DLF. In slices not stimulated, bicuculline plus strychnine failed to increase MOR internalization or NK1R internalization (two-way ANOVA not significant; $n=3$; data not shown). Results from slices stimulated in the presence and absence of bicuculline plus strychnine are shown in Figure 11. A two-way ANOVA revealed no significant effect of bicuculline plus strychnine, although in the medial portion of the slices there was a trend toward an increase in MOR and NK1R internalization. In any case, MOR internalization decreased toward the caudal portion, where it was negligible $(p<$ 0.01 for the "portion" variable). Therefore, even in the presence of bicuculline plus strychnine, opioid release was not induced by action potentials propagating down the DLF for more than two spinal segments.

\section{Discussion}

In conclusion, in the dorsal horn (1) primary afferents do not release opioids in amounts sufficient to activate MOR in neurons; (2) the main source of opioids are intrinsic neurons that release them when firing at high frequency; and (3) DLF stimulation did not produce detectable opioid release.

\section{Primary afferents do not release opioids}

We found that intensive stimulation of the dorsal root produced abundant NK1R internalization, indicative of neurokinin release (Marvizón et al., 2003), but no MOR internalization. In contrast, chemical (Song and Marvizón, 2003) and electrical stimulation of the dorsal horn readily produced MOR internalization by releasing opioids. We explored several stimulation patterns of the root, and all failed to produce MOR internalization. Moreover, capsaicin (Lever and Malcangio, 2002; Marvizón et al., 2003) and NMDA (Liu et al., 

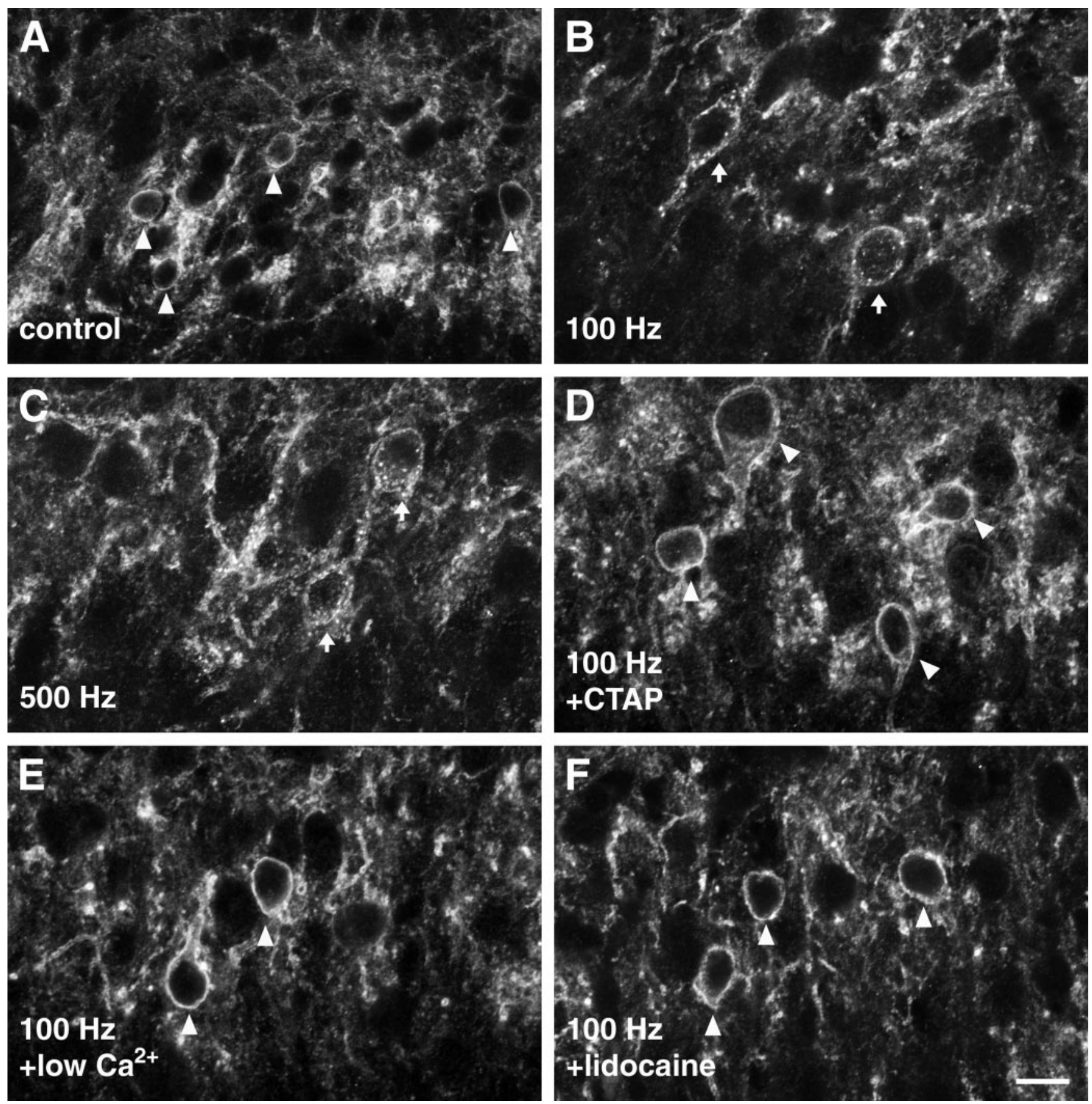

Figure 7. Confocal images of MOR neurons after dorsal horn stimulation. Coronal spinal cord slices were superfused with peptidase inhibitors alone $(A-C)$ or with $10 \mu \mathrm{M} C T A P(D)$, low $C a^{2+}(0.2$ mм) $(E)$, or $1 \mathrm{~mm}$ lidocaine $(F)$. One dorsal horn was stimulated (not stimulated for the control) $(A)$ with a single train of 1000 pulses at $100 \mathrm{~Hz}(B), 1000$ pulses at $500 \mathrm{~Hz}(C)$, or $3000 \mathrm{pulses}$ at 100 $\mathrm{Hz}(D-F)$. MOR were not internalized in any of the four neurons in $A$ (control). Internalization produced by $100 \mathrm{~Hz}$ stimulation is observed in two neurons in $B$ but was abolished in the presence of $C T A P(D)$, low $\mathrm{Ca}^{2+}(E)$, or lidocaine ( $F$. Abundant internalization is observed after $500 \mathrm{~Hz}$ stimulation (C). Dorsal is up, and all neurons are in lamina ll. Arrows and arrowheads indicate cells with and without internalization, respectively. Confocal images were taken at $100 \times$ (scale bar, $10 \mu \mathrm{m}$ ), except for $A$ (63X; scale bar, $16 \mu \mathrm{m})$, and consist of two optical sections ( 3 in C) separated $0.57 \mu \mathrm{m}$.

1997; Marvizón et al., 1997; Malcangio et al., 1998) produce neurokinin release from primary afferents but also failed to induce MOR internalization. Therefore, neurokinin-containing primary afferents do not release opioids, at least not in amounts sufficient to activate MOR in dorsal horn neurons. It is unlikely that opioids are released from other primary afferents, because they also would have been recruited by the dorsal root stimulation; however, primary afferents may still release minute amounts of opioids able to activate MOR in their terminals (Yaksh et al., 1980; Abbadie et al., 2001) or across synapses, although MOR neurons do not receive many synapses from C-fibers (Spike et al., 2002).

Some studies suggested that endomorphins colocalize with substance P in C-fiber terminals (Martin-Schild et al., 1998; Pierce et al., 1998; Spike et al., 2002) and may be co-released with it (Williams et al., 1999); however, any released endomorphins should have been able to produce MOR internalization because, when applied to slices, endomorphins potently induced MOR internalization and were not degraded by peptidases (Song and 
Table 2. Inhibition by CTAP, low $\mathrm{Ca}^{2+}$, and lidocaine of MOR internalization produced by dorsal horn stimulation

\begin{tabular}{lccc}
\hline Addition & \% MOR neurons with internalization & $n$ & Tukey's post-test \\
\hline None & $56 \pm 8$ & 6 & \\
CTAP $10 \mu \mathrm{M}$ & $1 \pm 1$ & 3 & $p<0.001$ \\
$\mathrm{Ca}^{2+} 0.2 \mathrm{mM}$ & $2 \pm 1$ & 3 & $p<0.001$ \\
Lidocaine $1 \mathrm{mM}$ & $1 \pm 1$ & 3 & $p<0.001$
\end{tabular}

Coronal spinal cord slices were superfused with aCSF containing peptidase inhibitors alone (None) or with $10 \mu \mathrm{N}$ CTAP, $0.2 \mathrm{~mm}$ instead of $2.4 \mathrm{~mm} \mathrm{CaCl}$, or $1 \mathrm{~mm}$ lidocaine. The stimulation electrode was positioned with its poles on either side of one dorsal horn and used to deliver a single train of 3000 pulses $(30 \mathrm{~V}, 0.4 \mathrm{msec})$ at $100 \mathrm{~Hz}$. Data are the percentage of MOR neurons with internalization in the stimulated dorsal horn; mean \pm SE of $n$ slices. One-way ANOVA yielded $p<0.0001$; Tukey's post-tests represent comparisons with the control (None).
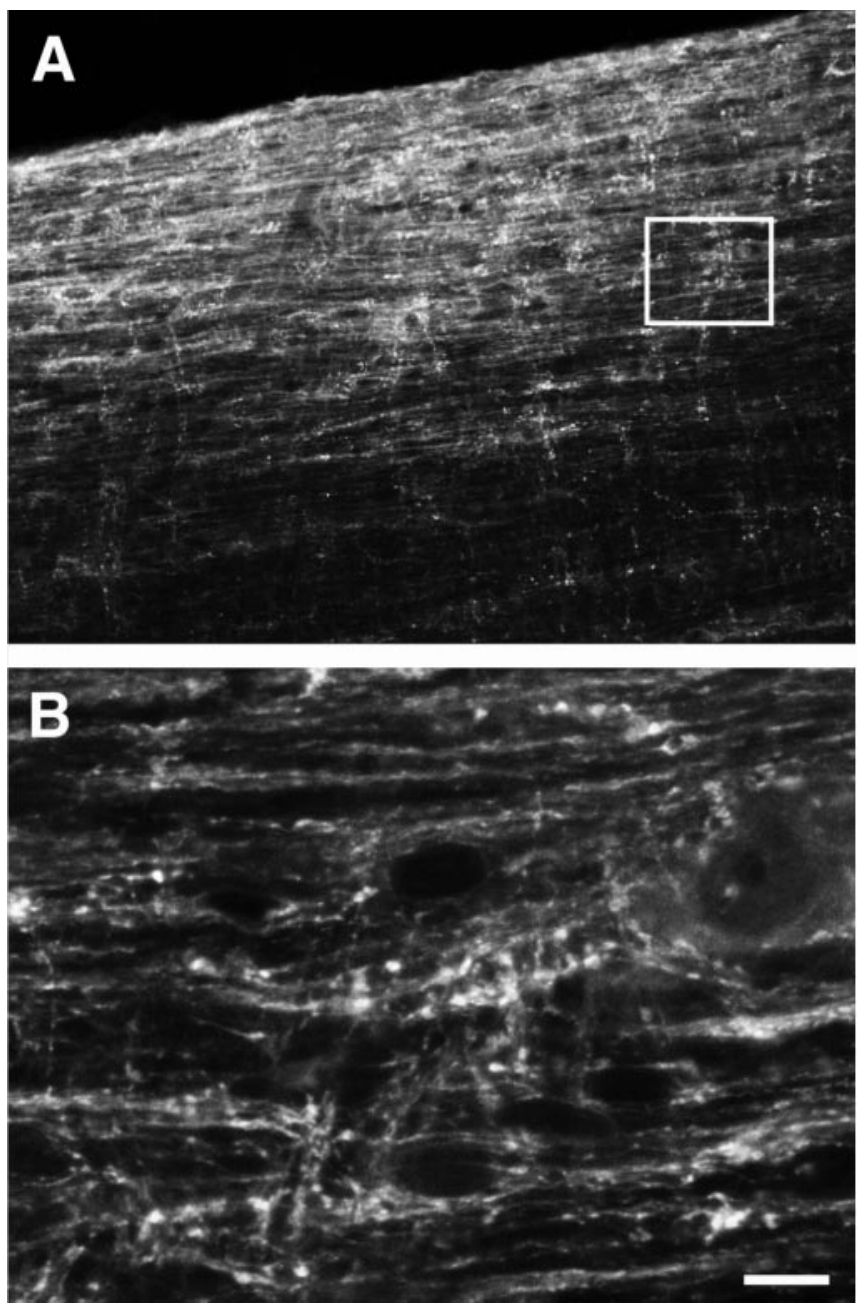

Figure 8. Presence of opioids in the DLF. Horizontal sections from rat spinal cord were labeled with monoclonal antibody $3 \mathrm{E} 7$, which recognizes endorphins, enkephalins, and dynorphins. A, Low-magnification ( $20 \times$; scale bar, $50 \mu \mathrm{m}$ ) image of the DLF consisting of three optical sections $2.5 \mu \mathrm{m}$ apart; $3 \mathrm{E} 7$-immunoreactive fibers are seen running in the rostrocaudal direction. The box represents the approximate location of the image in $B . B$, High-magnification $(100 \times$; scale bar, $10 \mu \mathrm{m})$ image consisting of three optical sections $0.57 \mu \mathrm{m}$ apart; 3E7immunoreactive fibers run mostly parallel and contain some intensely labeled puncta.

Marvizón, 2003). The discrepancy between our results and those of Williams et al. (1999) may be explained by the fact that they stimulated the "dorsal root entry zone," which would produce release from the dorsal horn. The presence of endomorphins in substance $\mathrm{P}$-containing terminals is far from established, because they were not found in dorsal root ganglia (Schreff et al., 1998). Importantly, some of antibodies raised against endomorphins cross-react with calcitonin gene-related peptide (CGRP) (Pierce
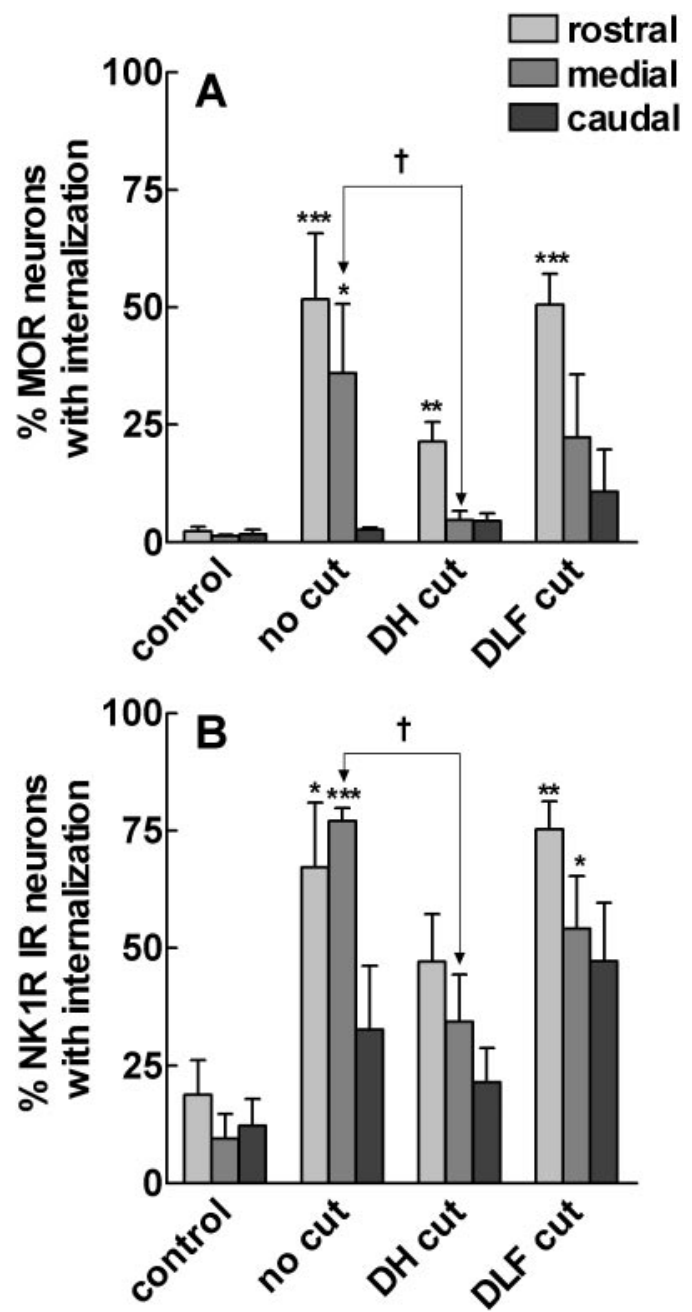

Figure 9. DLF stimulation in oblique slices. Oblique spinal cord slices were superfused with aCSF containing peptidase inhibitors. Some of the slices were left intact (no cut), whereas others were partially cut between $\mathrm{T} 13$ and L1, either across the entire width of the dorsal horn (DH cut) or across the entire width of the DLF (DLF cut). A bipolar electrode was positioned at T12 with its poles on either side of the DLF. In control slices no current was passed; all other slices were stimulated with 6000 pulses ( $20 \mathrm{~V}, 0.4 \mathrm{msec}$ ) delivered at $100 \mathrm{~Hz}$ in 60 trains of 100 pulses, 1 train every $10 \mathrm{sec}$. After fixation, slices were cut into three portions comprising segments T11T13 (rostral, where the electrode was placed and rostral to the cut), L1-L2 (medial), and L3-L4 (caudal). Sections from these portions were double labeled for MOR and NK1R, and internalization of MOR in laminas I-II neurons $(A)$ and NK1R in lamina I neurons $(B)$ was measured in the same sections. Data are the mean \pm SEM of three to five slices. Each panel was analyzed with a two-way ANOVA, and significant effects were found for the two variables stimulation (control, no cut, DH cut, or DLF cut; $p<0.001$ ) and portion (rostral, medial or caudal; $p<0.0001$ for MOR; $p<0.01$ for NK1R) but not their interaction. Bonferroni's post-test revealed the significant differences from control indicated by the asterisks $\left({ }^{*} \mathrm{p}<0.05\right.$; ${ }^{* *} \mathrm{p}<0.01$; ${ }^{* * *} \mathrm{p}<$ 0.001 ), and significant differences between the medial portions of no cut versus $\mathrm{DH}$ cut $\left({ }^{\dagger} p<\right.$ $0.05)$.

et al., 1998), probably because of their common amidated phenylalanine $\mathrm{C}$ terminus. CRGP colocalizes with substance $\mathrm{P}$ in primary afferents (Tuchscherer and Seybold, 1989), so this could explain why endomorphin-like immunoreactivity colocalizes with substance $P$ and decreases after rhizotomy. Indeed, using an anti-endomorphin antibody that does not cross-react with CGRP, we found no colocalization with substance P or CGRP (Marvizón and Song, 2002).

Our results also indicate that primary afferents do not release enkephalins or dynorphins, either directly or through synapses with dynorphin-containing neurons (Cho and Basbaum, 1989), 

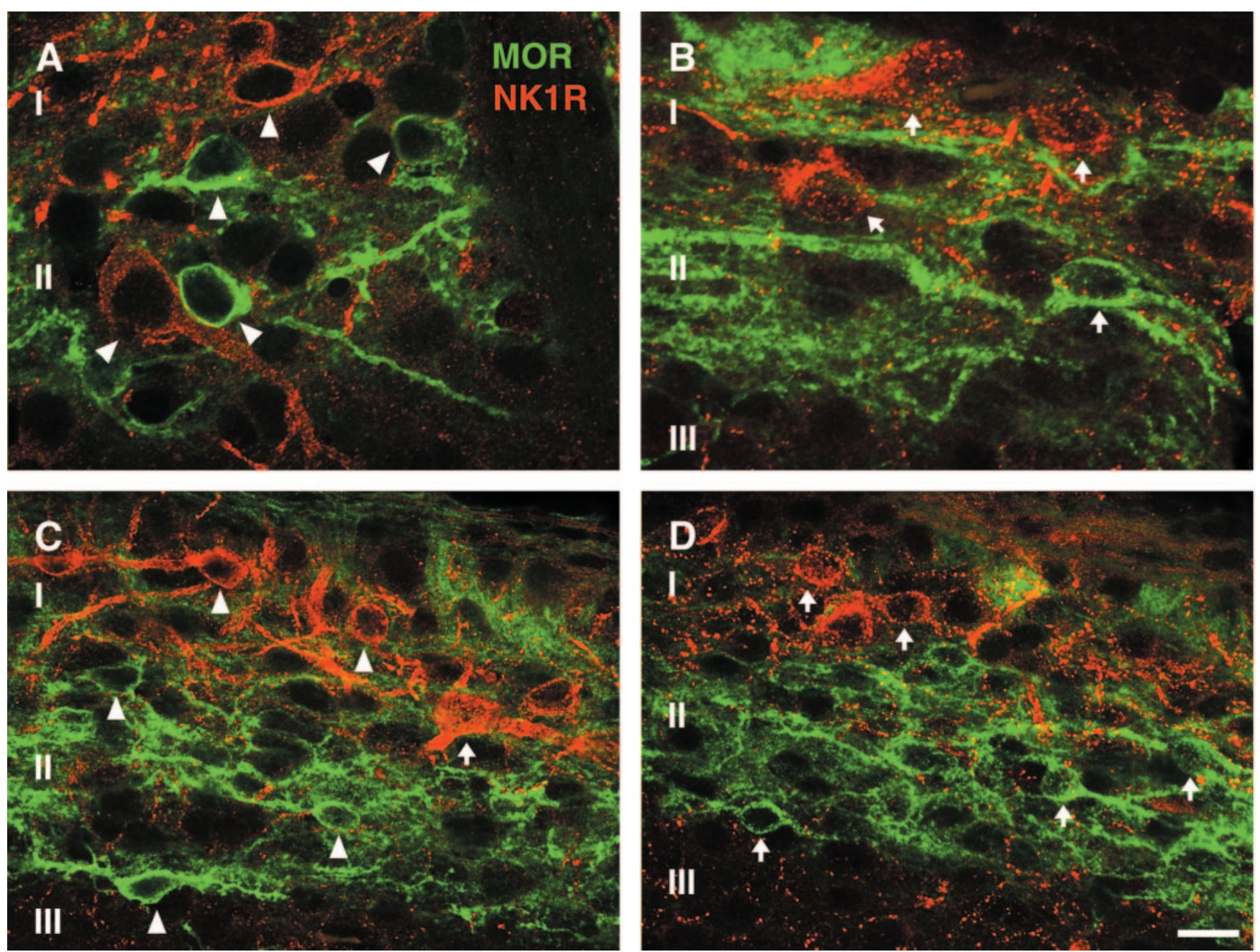

Figure 10. Confocal images of MOR and NK1R dorsal horn neurons after DLF stimulation. Oblique spinal cord slices were left intact $(A, B)$, cut at T13 across the dorsal horn ( $C$, or cut at $T 13$ across the DLF (D). Slices were superfused with peptidase inhibitors, and a stimulation electrode was positioned on the DLF at T12. $A$, Control: no current was passed. $B-D$, Slices were stimulated with 6000 pulses in 60 trains at $100 \mathrm{~Hz}$. Sections from the slices were double labeled for MOR (green) and NK1R (red). Images are from the medial portion (segments L1-L2), an area situated on the other side of the cut (in $($ and $D$ ) from the stimulation site. Roman numerals indicate the approximate position of laminas I-III. Arrows and arrowheads indicate cells with and without internalization, respectively. Confocal images were taken at $100 \times$ for $A$ and $B$ (scale bar, $10 \mu \mathrm{m}$ ) and at $63 \times$ for ( and $D$ (scale bar, $16 \mu \mathrm{m}$ ) and consist of two optical sections, except for $B(3$ optical sections). Little MOR or NK1 R internalization was observed in control slices $(A)$. Substantial MOR and NK1R internalization was observed after DLF stimulation $(B)$, even when the DLF was cut $(D)$, but not when the dorsal horn was cut $(C)$.

because they produced MOR internalization when applied to the slices (Song and Marvizón, 2003). Indeed, primary afferents do not contain enkephalins (Pohl et al., 1994), and those that contain dynorphins may be restricted to sacral segments (Basbaum et al., 1986; Sweetnam et al., 1986). Although sciatic nerve stimulation produced spinal opioid release (Yaksh and Elde, 1980, 1981; Nyberg et al., 1983; Iadarola et al., 1986; Hutchison et al., 1990; Klein et al., 1991), it appears to be from intrinsic dorsal horn neurons and to require supraspinal modulation (Hutchison et al., 1990).

\section{Frequency-dependent opioid release from intrinsic dorsal horn neurons}

Our results indicate that the main source of opioids that activate MOR in neurons is other intrinsic dorsal horn neurons (Todd and Spike, 1993), given that dorsal horn stimulation, but not dorsal root stimulation or DLF stimulation, produced MOR internalization. This internalization was mediated by opioid release, because it was abolished by lidocaine, low $\mathrm{Ca}^{2+}$, the absence of peptidase inhibitors, and CTAP, indicating that it required firing of action potentials, $\mathrm{Ca}^{2+}$-dependent release, presence of extracellular peptides, and agonist binding to MOR, respectively.

MOR internalization showed a pronounced frequency dependence, being negligible at frequencies under $10 \mathrm{~Hz}$ and maximal at $500 \mathrm{~Hz}$. This indicates the presence of specialized mechanisms controlling opioid release. Indeed, the release of each particular neuropeptide appears to be encoded in firing patterns (Brezina et al., 2000) because their different release mechanisms depend on either the rapid $\mathrm{Ca}^{2+}$ raises produced by individual action potentials or the residual $\mathrm{Ca}^{2+}$ levels produced by the cumulative effect of high-frequency firing (Muschol and Salzberg, 2000). Furthermore, the high-frequency firing rates that trigger opioid release may require the integration by opioid-containing interneurons of signals from multiple sources.

\section{Electrical stimulation of the DLF did not release opioids}

We expected that DLF stimulation would produce opioid release and thus MOR internalization of the dorsal horn. Stimulation of the PAG-RVM-dorsal horn pathway produces potent analgesia 

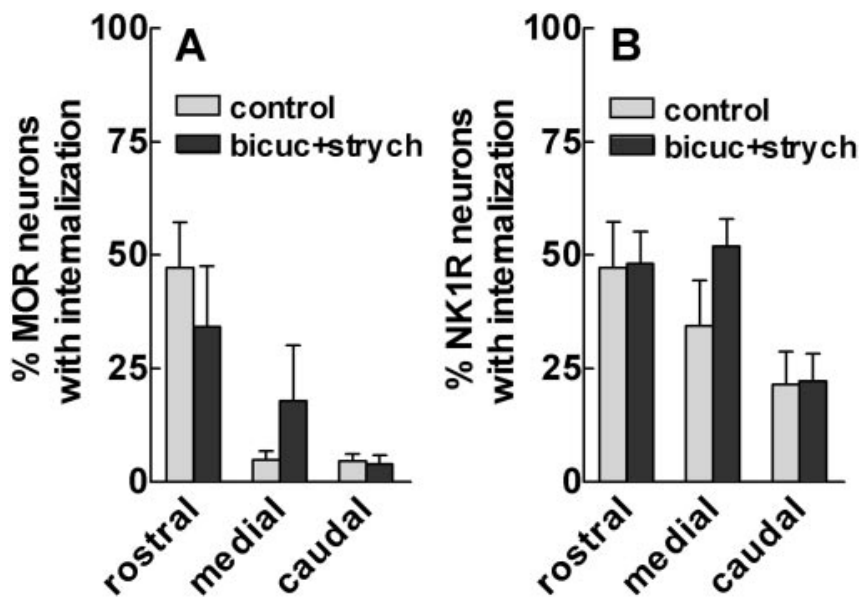

Figure 11. DLFstimulation in the presence of $G A B A_{A}$ and glycine antagonists. Oblique spinal cord slices were cut across the entire width of the dorsal horn at T13 and superfused with peptidase inhibitors alone (control; same data as DH cut in Fig. 9, included here for comparison) or with $5 \mu \mathrm{m}$ bicuculline and $2 \mu \mathrm{m}$ strychnine (bicuc + strych). A bipolar electrode was positioned at T12 with its poles on either side of the DLF and used to stimulate the slices with 6000 pulses ( $20 \mathrm{~V}, 0.4 \mathrm{msec}$ ) delivered at $100 \mathrm{~Hz}$ in 60 trains of 100 pulses. Slices were cut into three portions comprising segments T11-T13 (rostral, where the electrode was placed and rostral to the cut), L1-L2 (medial), and L3-L4 (caudal). Sections from these portions were double labeled for MOR and NK1R, and internalization of MOR in laminas I-II neurons $(A)$ and NK1R in lamina Ineurons $(B)$ was measured in the same sections. Data are the mean \pm SEM of five to six slices. Each panel was analyzed with a two-way ANOVA, the two variables being drug (control vs bicuc + strych) and portion (rostral, medial, and caudal). Only the variable portion had a significant effect $(p<0.01)$. Bonferroni's post-test revealed no significant effect of drug for any of the three portions.

(Basbaum et al., 1976; Basbaum and Fields, 1984; Fields et al., 1991; Mason, 1999), which is thought to be mediated, at least in part, by spinal opioid release and MOR activation (Budai and Fields, 1998). Moreover, we found that fibers that run rostrocaudally in the DLF contain opioids and hence may release them directly in addition to evoking their release from dorsal horn neurons; however, although DLF stimulation produced MOR internalization near the site of stimulation, it failed to produce internalization in regions farther than three spinal segments from it, as would be expected if descending axons from the RVM were recruited (Fields et al., 1995). Quite the opposite, by cutting the slices across the dorsal horn or the DLF, we showed that the MOR internalization was attributable to signals traveling through the dorsal horn and not via the DLF.

Hence there is a discrepancy between the ability of PAG stimulation to produce analgesia mediated by spinal MORs (Budai and Fields, 1998) and the presence of opioid immunoreactivity in DLF fibers, on the one hand, and the failure of DLF stimulation to produce MOR internalization, on the other. The most likely explanation for this discrepancy is that DLF stimulation recruited fibers that inhibited opioid release from opioid-containing DLF fibers and dorsal horn neurons receiving synapses from them. Indeed, two distinct populations of RVM neurons send axons down the DLF into the dorsal horn (Fields et al., 1995; Mason, 1999): the OFF cells, which produce analgesia, and the ON cells, which produce hyperalgesia. ON and OFF cells have similar properties in terms of size and firing rates (Leung and Mason, 1998), so it is likely that their axons were equally recruited by the DLF stimulation. ON and OFF cells may inhibit and stimulate opioid release, respectively, mirroring their mutual inhibition in the nucleus raphe magnus, which is mediated by $\mathrm{GABA}_{\mathrm{A}}$ receptors (Fields et al., 1991). DLF stimulation in the presence of a
$\mathrm{GABA}_{\mathrm{A}}$ antagonist, however, still failed to produce MOR internalization. This inhibition of opioid release could be mediated by other neurotransmitter systems, perhaps involving serotonergic or noradrenergic axons from the RVM, which also travel down the DLF (Mason, 1999). An alternative explanation is that we did not find the right conditions to stimulate the DLF; however, the pulse intensity and number used were effective to stimulate opioid-containing dorsal horn neurons. Lower-frequency (20 $\mathrm{Hz}$ ) stimulation of the DLF was ineffective, and OFF cells do not appear to fire at frequencies $>100 \mathrm{~Hz}$ (Leung and Mason, 1998).

\section{Physiological implications}

Our findings are consistent with other studies showing that opioid release in the spinal cord is subject to a complex modulation by environmental and physiological factors. For example, the release of Met-enkephalin in the rat spinal cord was increased by noxious stimulation of the muzzle but inhibited by noxious stimulation of the tail (Cesselin et al., 1985). Moreover, different nociceptive modalities appear to produce opioid release through different neuronal pathways. Thermal and chemical noxious stimuli elicited Met-enkephalin release from the same spinal cord segment receiving the stimulus (Cesselin et al., 1989; Bourgoin et al., 1990), whereas mechanical noxious stimuli elicited its release from spinal segments unrelated to the stimulated area (Le Bars et al., 1987a,b). Furthermore, electro-acupuncture at high frequency $(100 \mathrm{~Hz})$ elicited dynorphin release in the spinal cord, whereas at low frequency $(2 \mathrm{~Hz})$ it elicited enkephalin release (Han, 2003). These effects were mediated supraspinally: the former by the parabrachial nucleus and the later by the arcuate nucleus. It is not clear, however, whether supraspinal structures are involved in the release of Met-enkephalin evoked by sciatic nerve stimulation. In one study (Yaksh and Elde, 1981) it was unaffected by cold block of the spinal cord, whereas in another (Hutchison et al., 1990) it was abolished by spinal transection. Importantly, spinal opioid release may be driven only partially by noxious stimuli (Trafton et al., 2000), depending more strongly on other factors like stress or attention (Mayer, 2000). Our findings suggest that opioids are released when signals from different sources (which may include primary afferents, the RVM, and the spinal cord) are integrated by dorsal horn neurons, causing them to fire at very high frequencies.

\section{References}

Abbadie C, Trafton J, Liu H, Mantyh PW, Basbaum AI (1997) Inflammation increases the distribution of dorsal horn neurons that internalize the neurokinin-1 receptor in response to noxious and non-noxious stimulation. J Neurosci 17:8049-8060.

Abbadie C, Pasternak GW, Aicher SA (2001) Presynaptic localization of the carboxy-terminus epitopes of the mu opioid receptor splice variants MOR-1C and MOR-1D in the superficial laminae of the rat spinal cord. Neuroscience 106:833-842.

Afrah AW, Stiller CO, Olgart L, Brodin E, Gustafsson H (2001) Involvement of spinal $\mathrm{N}$-methyl-D-aspartate receptors in capsaicin-induced in vivo release of substance $\mathrm{P}$ in the rat dorsal horn. Neurosci Lett 316:83-86.

Aimone LD, Yaksh TL (1989) Opioid modulation of capsaicin-evoked release of substance $\mathrm{P}$ from rat spinal cord in vivo. Peptides 10:1127-1131.

Allen BJ, Rogers SD, Ghilardi JR, Menning PM, Kuskowski MA, Basbaum AI, Simone DA, Mantyh PW (1997) Noxious cutaneous thermal stimuli induce a graded release of endogenous substance $\mathrm{P}$ in the spinal cord: imaging peptide action in vivo. J Neurosci 17:5921-5927.

Allen BJ, Li J, Menning PM, Rogers SD, Ghilardi J, Mantyh PW, Simone DA (1999) Primary afferent fibers that contribute to increased substance P receptor internalization in the spinal cord after injury. J Neurophysiol 81:1379-1390.

Alvarez VA, Arttamangkul S, Dang V, Salem A, Whistler JL, von Zastrow M, Grandy DK, Williams JT (2002) $\mu$-Opioid receptors: ligand-dependent 
activation of potassium conductance, desensitization, and internalization. J Neurosci 22:5769-5776.

Arvidsson U, Riedl M, Chakrabarti S, Lee JH, Nakano AH, Dado RJ, Loh HH, Law PY, Wessendorf MW, Elde R (1995) Distribution and targeting of a $\mu$-opioid receptor MOR1 in brain and spinal cord. J Neurosci 15:3328-3341.

Basbaum AI, Fields HL (1979) The origin of descending pathways in the dorsolateral funiculus of the spinal cord of the cat and rat: further studies on the anatomy of pain modulation. J Comp Neurol 187:513-531.

Basbaum AI, Fields HL (1984) Endogenous pain control systems: brainstem spinal pathways and endorphin circuitry. Annu Rev Neurosci 7:309-338.

Basbaum AI, Clanton CH, Fields HL (1976) Opiate and stimulus-produced analgesia: functional anatomy of a medullospinal pathway. Proc Natl Acad Sci USA 73:4685-4688.

Basbaum AI, Cruz L, Weber E (1986) Immunoreactive dynorphin B in sacral primary afferent fibers of the cat. J Neurosci 6:127-133.

Bourgoin S, Le Bars D, Clot AM, Hamon M, Cesselin F (1990) Subcutaneous formalin induces a segmental release of Met-enkephalin-like material from the rat spinal cord. Pain 41:323-329.

Brezina V, Church PJ, Weiss KR (2000) Temporal pattern dependence of neuronal peptide transmitter release: models and experiments. J Neurosci 20:6760-6772

Budai D, Fields HL (1998) Endogenous opioid peptides acting at mu-opioid receptors in the dorsal horn contribute to midbrain modulation of spinal nociceptive neurons. J Neurophysiol 79:677-687.

Cesselin F, Le Bars D, Bourgoin S, Artaud F, Gozlan H, Clot AM, Besson JM, Hamon M (1985) Spontaneous and evoked release of methionineenkephalin-like material from the rat spinal cord in vivo. Brain Res 339:305-313.

Cesselin F, Bourgoin S, Clot AM, Hamon M, Le Bars D (1989) Segmental release of met-enkephalin-like material from the spinal-cord of rats, elicited by noxious thermal stimuli. Brain Res 484:71-77.

Cho HJ, Basbaum AI (1989) Ultrastructural analysis of dynorphin B-immunoreactive cells and terminals in the superficial dorsal horn of the deafferented spinal cord of the rat. J Comp Neurol 281:193-205.

Courtney KR, Strichartz GR (1987) Structural elements which determine local anesthetic activity. In: Local anesthetics (Strichartz GR, ed), pp 5394. New York: Springer.

Eckersell CB, Popper P, Micevych PE (1998) Estrogen-induced alteration of $\mu$-opioid receptor immunoreactivity in the medial preoptic nucleus and medial amygdala. J Neurosci 18:3967-3976.

Fields HL, Heinricher MM, Mason P (1991) Neurotransmitters in nociceptive modulatory circuits. Annu Rev Neurosci 14:219-245.

Fields HL, Malick A, Burstein R (1995) Dorsal horn projection targets of $\mathrm{ON}$ and OFF cells in the rostral ventromedial medulla. J Neurophysiol 74:1742-1759.

Go VLW, Yaksh TL (1987) Release of substance P from the cat spinal cord. J Physiol (Lond) 391:141-167.

Grady EF, Baluk P, Bohm S, Gamp PD, Wong H, Payan DG, Ansel J, Portbury AL, Furness JB, McDonald DM, Bunnett NW (1996) Characterization of antisera specific to NK1, NK2, and NK3 neurokinin receptors and their utilization to localize receptors in the rat gastrointestinal tract. J Neurosci 16:6975-6986.

Gramsch C, Meo T, Riethmuller G, Herz A (1983) Binding characteristics of a monoclonal beta-endorphin antibody recognizing the N-terminus of opioid peptides. J Neurochem 40:1220-1226.

Han JS (2003) Acupuncture: neuropeptide release produced by electrical stimulation of different frequencies. Trends Neurosci 26:17-22.

Honore P, Menning PM, Rogers SD, Nichols ML, Basbaum AI, Besson JM, Mantyh PW (1999) Spinal cord substance P receptor expression and internalization in acute, short-term, and long-term inflammatory pain states. J Neurosci 19:7670-7678.

Hutchison WD, Morton CR, Terenius L (1990) Dynorphin A: in vivo release in the spinal cord of the cat. Brain Res 532:299-306.

Iadarola MJ, Tang J, Costa E, Yang HY (1986) Analgesic activity and release of [MET5] enkephalin-Arg6-Gly7-Leu8 from rat spinal cord in vivo. Eur J Pharmacol 121:39-48.

Johnson JW, Ascher P (1987) Glycine potentiates the NMDA response in cultured mouse brain neurons. Nature 325:529-531.

Kanjhan R (1995) Opioids and pain. Clin Exp Pharmacol Physiol 22:397-403.

Keith DE, Murray SR, Zaki PA, Chu PC, Lissin DV, Kang L, Evans CJ, von
Zastrow M (1996) Morphine activates opioid receptors without causing their rapid internalization. J Biol Chem 271:19021-19024.

Keith DE, Anton B, Murray SR, Zaki PA, Chu PC, Lissin DV, MonteilletAgius G, Stewart PL, Evans CJ, von Zastrow M (1998) $\mu$-Opioid receptor internalization: opiate drugs have differential effects on a conserved endocytic mechanism in vitro and in the mammalian brain. Mol Pharmacol 53:377-384.

Kemp T, Spike RC, Watt C, Todd AJ (1996) The mu-opioid receptor (MOR1) is mainly restricted to neurons that do not contain GABA or glycine in the superficial dorsal horn of the rat spinal cord. Neuroscience 75:1231-1238.

Klein CM, Sorkin LS, Chung K, Coggeshall RE (1991) Unmyelinated primary afferent fiber stimulation depletes dynorphin A (1-8) immunoreactivity in rat ventral horn. Brain Res 566:70-76.

Koslow M, Bak A, Li CL (1973) C-fiber excitability in the cat. Exp Neurol 41:745-753.

Laing I, Todd AJ, Heizmann CW, Schmidt HH (1994) Subpopulations of GABAergic neurons in laminae I-III of rat spinal dorsal horn defined by coexistence with classical transmitters, peptides, nitric oxide synthase or parvalbumin. Neuroscience 61:123-132.

Lao L, Song B, Marvizón JCG (2003) Neurokinin release produced by capsaicin acting on the central terminals and axons of primary afferents: relationship with NMDA and $\mathrm{GABA}_{\mathrm{B}}$ receptors. Neuroscience, in press.

Le Bars D, Bourgoin S, Clot AM, Hamon M, Cesselin F (1987a) Noxious mechanical stimuli increase the release of Met-enkephalin-like material heterosegmentally in the rat spinal cord. Brain Res 402:188-192.

Le Bars D, Bourgoin S, Villanueva L, Clot AM, Hamon M, Cesselin F (1987b) Involvement of the dorsolateral funiculi in the spinal release of metenkephalin-like material triggered by heterosegmental noxious mechanical stimuli. Brain Res 412:190-195.

Leung CG, Mason P (1998) Physiological survey of medullary raphe and magnocellular reticular neurons in the anesthetized rat. J Neurophysiol 80:1630-1646.

Lever IJ, Malcangio M (2002) CB(1) receptor antagonist SR141716A increases capsaicin-evoked release of substance $\mathrm{P}$ from the adult mouse spinal cord. Br J Pharmacol 135:21-24.

Lever IJ, Bradbury EJ, Cunningham JR, Adelson DW, Jones MG, McMahon SB, Marvizón JC, Malcangio M (2001) Brain-derived neurotrophic factor is released in the dorsal horn by distinctive patterns of afferent fiber stimulation. J Neurosci 21:4469-4477.

Li CL, Bak A (1976) Excitability characteristics of the A- and C-fibers in a peripheral nerve. Exp Neurol 50:67-79.

Liu H, Wang H, Sheng M, Jan LY, Jan YN, Basbaum AI (1994) Evidence for presynaptic $N$-methyl-D-aspartate autoreceptors in the spinal cord dorsal horn. Proc Natl Acad Sci USA 91:8383-8387.

Liu H, Mantyh PW, Basbaum AI (1997) NMDA-receptor regulation of substance $P$ release from primary afferent nociceptors. Nature 386:721-724.

Malcangio M, Fernandes K, Tomlinson DR (1998) NMDA receptor activation modulates evoked release of substance $\mathrm{P}$ from rat spinal cord. $\mathrm{Br} \mathrm{J}$ Pharmacol 125:1625-1626.

Mansour A, Fox CA, Akil H, Watson SJ (1995) Opioid-receptor mRNA expression in the rat CNS: anatomical and functional implications. Trends Neurosci 18:22-29.

Mantyh PW, DeMaster E, Malhotra A, Ghilardi JR, Rogers SD, Mantyh CR, Liu H, Basbaum AI, Vigna SR, Maggio JE (1995) Receptor endocytosis and dendrite reshaping in spinal neurons after somatosensory stimulation. Science 268:1629-1632.

Martin-Schild S, Gerall AA, Kastin AJ, Zadina JE (1998) Endomorphin-2 is an endogenous opioid in primary sensory afferent fibers. Peptides 19:1783-1789.

Marvizón JCG, Song B (2002) Opioids are not co-released with neurokinins from primary afferent terminals in the rat dorsal horn. Soc Neurosci Abstr 28:259.4.

Marvizón JCG, Martinez V, Grady EF, Bunnett NW, Mayer EA (1997) Neurokinin 1 receptor internalization in spinal cord slices induced by dorsal root stimulation is mediated by NMDA receptors. J Neurosci 17:8129-8136.

Marvizón JCG, Grady EF, Wazsak-McGee J, Mayer EA (1999a) Internalization of $\mu$-opioid receptors in rat spinal cord slices. NeuroReport 10:2329-2334

Marvizón JCG, Grady EF, Stefani E, Bunnett NW, Mayer EA (1999b) Substance $\mathrm{P}$ release in the dorsal horn assessed by receptor internalization: 
NMDA receptors counteract a tonic inhibition by GABA(B) receptors. Eur J Neurosci 11:417-426.

Marvizón JCG, Adelson DW, Mayer EA (2000) Frequency-dependence of neurokinin release measured by NK1 receptor internalization. Soc Neurosci Abstr 26:246.16.

Marvizón JCG, McRoberts JA, Ennes HS, Song B, Wang X, Jinton L, Corneliussen B, Mayer EA (2002) Two N-methyl-D-aspartate receptors in rat dorsal root ganglia with different subunit composition and localization. J Comp Neurol 446:325-341.

Marvizón JCG, Wang X, Matsuka Y, Neubert JK, Spigelman I (2003) Relationship between capsaicin-evoked substance P release and NK1 receptor internalization in the rat dorsal horn. Neuroscience 118:535-545.

Mason P (1999) Central mechanisms of pain modulation. Curr Opin Neurobiol 9:436-441.

Mayer DJ (2000) Biological mechanisms of acupuncture. Prog Brain Res 122:457-477.

Muschol M, Salzberg BM (2000) Dependence of transient and residual calcium dynamics on action-potential patterning during neuropeptide secretion. J Neurosci 20:6773-6780.

Nyberg F, Yaksh TL, Terenius L (1983) Opioid activity released from cat spinal cord by sciatic nerve stimulation. Life Sci 33[Suppl 1]:17-20.

Pierce TL, Grahek MD, Wessendorf MW (1998) Immunoreactivity for endomorphin-2 occurs in primary afferents in rats and monkey. NeuroReport 9:385-389.

Pohl M, Collin E, Bourgoin S, Conrath M, Benoliel JJ, NEVO I, Hamon M, Giraud P, Cesselin F (1994) Expression of preproenkephalin-A gene and presence of Met-enkephalin in dorsal root ganglia of the adult rat. J Neurochem 63:1226-1234.

Powell JJ, Todd AJ (1992) Light and electron microscope study of GABAimmunoreactive neurones in lamina III of rat spinal cord. J Comp Neurol 315:125-136

Przewlocki R, Przewlocka B (2001) Opioids in chronic pain. Eur J Pharmacol 429:79-91.

Quirion R (1984) Pain, nociception and spinal opioid receptors. Prog Neuropsychopharmacol Biol Psychiatry 8:571-579.

Randic M, Jiang MC, Cerne R (1993) Long-term potentiation and longterm depression of primary afferent neurotransmission in the rat spinal cord. J Neurosci 13:5228-5241.

Ribeiro-da-Silva A, Claudio Cuello A (1995) Organization of peptidergic neurons in the dorsal horn of the spinal cord: anatomical and functional correlates. Prog Brain Res 104:41-59.

Sandkuhler J, Chen JG, Cheng G, Randic M (1997) Low-frequency stimulation of afferent $\mathrm{A} \delta$-fibers induces long-term depression at primary afferent synapses with substantia gelatinosa neurons in the rat. J Neurosci 17:6483-6491.

Schreff M, Schulz S, Wiborny D, Heollt V (1998) Immunofluorescent identification of endomorphin-2-containing nerve fibers and terminals in the rat brain and spinal cord. NeuroReport 9:1031-1034.

Skinner K, Fields HL, Basbaum AI, Mason P (1997) GABA-immunoreactive boutons contact identified OFF and ON cells in the nucleus raphe magnus. J Comp Neurol 378:196-204.

Song B, Marvizón JC (2003) Peptidases prevent $\mu$-opioid receptor internalization in dorsal horn neurons by endogenously released opioids. J Neurosci 23:1847-1858.
Spike RC, Puskar Z, Sakamoto H, Stewart W, Watt C, Todd AJ (2002) MOR-1-immunoreactive neurons in the dorsal horn of the rat spinal cord: evidence for nonsynaptic innervation by substance P-containing primary afferents and for selective activation by noxious thermal stimuli. Eur J Neurosci 15:1306-1316.

Sweetnam PM, Wrathall JR, Neale JH (1986) Localization of dynorphin gene product-immunoreactivity in neurons from spinal cord and dorsal root ganglia. Neuroscience 18:947-955.

Swett JE, Bourassa CM (1981) Electrical stimulation of peripheral nerve. In: Electrical stimulation research techniques (Patterson MM, Kesner RP, eds), pp 243-295. New York: Academic.

Todd AJ, McKenzie J (1989) GABA-immunoreactive neurons in the dorsal horn of the rat spinal cord. Neuroscience 31:799-806.

Todd AJ, Spike RC (1993) The localization of classical transmitters and neuropeptides within neurons in laminae I-III of the mammalian spinal dorsal horn. Prog Neurobiol 41:609-645.

Todd AJ, Sullivan AC (1990) Light microscope study of the coexistence of GABA-like and glycine-like immunoreactivities in the spinal cord of the rat. J Comp Neurol 296:496-505.

Todd AJ, Watt C, Spike RC, Sieghart W (1996) Colocalization of GABA, glycine, and their receptors at synapses in the rat spinal cord. J Neurosci 16:974-982.

Trafton JA, Abbadie C, Marchand S, Mantyh PW, Basbaum AI (1999) Spinal opioid analgesia: how critical is the regulation of substance P signaling? J Neurosci 19:9642-9653.

Trafton JA, Abbadie C, Marek K, Basbaum AI (2000) Postsynaptic signaling via the $\mu$-opioid receptor: responses of dorsal horn neurons to exogenous opioids and noxious stimulation. J Neurosci 20:8578-8584

Trafton JA, Abbadie C, Basbaum AI (2001) Differential contribution of substance $\mathrm{P}$ and neurokinin A to spinal cord neurokinin-1 receptor signaling in the rat. J Neurosci 21:3656-3664.

Tuchscherer MM, Seybold VS (1989) A quantitative study of the coexistence of peptides in varicosities within the superficial laminae of the dorsal horn of the rat spinal cord. J Neurosci 9:195-205.

Williams CA, Wu SY, Dun SL, Kwok EH, Dun NJ (1999) Release of endomorphin-2 like substances from the rat spinal cord. Neurosci Lett 273:25-28.

Yaksh TL (1987) Spinal opiates: a review of their effect on spinal function with emphasis on pain processing. Acta Anaesthesiol Scand [Suppl] 85:25-37.

Yaksh TL, Elde RP (1980) Release of methionine-enkephalin immunoreactivity from the rat spinal cord in vivo. Eur J Pharmacol 63:359-362.

Yaksh TL, Elde RP (1981) Factors governing release of methionine enkephalin-like immunoreactivity from mesencephalon and spinal cord of the cat in vivo. J Neurophysiol 46:1056-1075.

Yaksh TL, Jessell TM, Gamse R, Mudge AW, Leeman SE (1980) Intrathecal morphine inhibits substance $\mathrm{P}$ release from mammalian spinal cord in vivo. Nature 286:155-157.

Yaksh TL, Terenius L, Nyberg F, Jhamandas K, Wang JY (1983) Studies on the release by somatic stimulation from rat and cat spinal cord of active materials which displace dihydromorphine in an opiate-binding assay. Brain Res 268:119-128. 